\title{
BMJ Open Expectations and experiences of hospital postnatal care in the UK: a systematic review of quantitative and qualitative studies
}

Reem Malouf, Jane Henderson, Fiona Alderdice

To cite: Malouf R, Henderson J, Alderdice F. Expectations and experiences of hospital postnata care in the UK: a systematic review of quantitative and qualitative studies. BMJ Open 2019:9:e022212. doi:10.1136/ bmjopen-2018-022212

- Prepublication history and additional material for this paper are available online. To view please visit the journal online (http://dx.doi.org/10.1136/ bmjopen-2018-022212)

Received 13 February 2018 Revised 20 March 2019 Accepted 8 May 2019
Check for updates

(C) Author(s) (or their employer(s)) 2019. Re-use permitted under CC BY-NC. No commercial re-use. See rights and permissions. Published by BMJ.

Nuffield Department of Population Health, National Perinatal Epidemiology Unit, Oxford, UK

Correspondence to Professor Fiona Alderdice; fiona.alderdice@npeu.ox.ac.uk

\section{ABSTRACT}

Objectives To report on women's and families' expectations and experiences of hospital postnatal care, and also to reflect on women's satisfaction with hospital postnatal care and to relate their expectations to their actual care experiences.

Design Systematic review.

Setting UK.

Participants Postnatal women.

Primary and secondary outcomes Women's and families' expectations, experiences and satisfaction with hospital postnatal care.

Methods Embase, MEDLINE, PsycINFO, Applied Social Sciences Index and Abstracts, Cumulative Index to Nursing and Allied Health (CINAHL Plus), Science Citation Index, and Social Sciences Citation Index were searched to identify relevant studies published since 1970 . We incorporated findings from qualitative, quantitative and mixed-methods studies. Eligible studies were independently screened and quality-assessed using a modified version of the National Institutes of Health Quality Assessment Tool for quantitative studies and the Critical Appraisal Skills Programme for qualitative studies. Data were extracted on participants' characteristics, study period, setting, study objective and study specified outcomes, in addition to the summary of results.

Results Data were included from 53 studies, of which 28 were quantitative, 19 were qualitative and 6 were mixed-methods studies. The methodological quality of the included studies was mixed, and only three were completely free from bias. Women were generally satisfied with their hospital postnatal care but were critical of staff interaction, the ward environment and infant feeding support. Ethnic minority women were more critical of hospital postnatal care than white women. Although duration of postnatal stay has declined over time, women were generally happy with this aspect of their care. There was limited evidence regarding women's expectations of postnatal care, families' experience and social disadvantage.

Conclusion Women were generally positive about their experiences of hospital postnatal care, but improvements could still be made. Individualised, flexible models of postnatal care should be evaluated and implemented.

PROSPERO registration number CRD42017057913.
Strengths and limitations of this study

We searched across 10 different databases.

- Quality assessment and data extraction were performed by the authors independently of each other.

- Although the aim was to focus on women and babies without complications, most studies did not differentiate by risk.

- We initially planned to focus on hospital postnatal care, but some studies did not differentiate between hospital and community postnatal care. These were included for completeness.

\section{INTRODUCTION}

The key aspects of postnatal care include attention to the physical health of the mother, breastfeeding support, psychological wellbeing of parents, and education as to what the woman should expect after birth and regarding infant care. Over time there have been a number of changes in postnatal care in the UK, the most evident being a reduction in length of hospital stay. ${ }^{1}$ A hospital lying-in period of between 8 and 14 days was standard in the $1950 \mathrm{~s},{ }^{2}$ whereas length of postnatal hospital stay for a woman with an uncomplicated vaginal birth in the UK is now often 1-2 days. $^{34}$

A Cochrane review by Brown et a $a \bar{l}$ on length of postnatal hospital stay for healthy mothers who gave birth to healthy term babies suggests that early discharge home does not have an adverse effect on maternal health or breastfeeding outcomes when accompanied by a policy of offering women at least one nurse-midwife home visit. ${ }^{5}$ Most trials included assessments of women's satisfaction with postnatal care in hospital, and overall, while not statistically significant, women tended to favour a short postnatal stay. A trial by Waldenström et at $t^{6}$ also reported that, following early discharge, fathers were more involved in early care of 
the infant. The Cochrane review has not been updated since 2002, and the current state of evidence regarding the impact of length of postnatal hospital stay is unclear, particularly regarding current UK postnatal care policy and practice.

More choices around place of birth means that women may have more variation in location for the immediate postnatal period, for example, a stand-alone birth centre (midwife-led units where the emphasis is on birth without medical intervention in a homely environment) in comparison with a hospital maternity unit. Content of care has also changed. Maternal health observations, feeding support and parental education all remain priorities, but there are limits to what can be achieved during a short stay. In addition, national guidance recommends that women are asked about their emotional well-being at every contact and that they have an initial assessment of needs and individualised plan of care, all of which require time. ${ }^{7}$ Better Births: Improving outcomes of maternity services in England ${ }^{8}$ acknowledges that postnatal care needs to be resourced appropriately and that women should have access to their midwife (and where appropriate obstetrician) as required after having had their baby. The Maternity Transformation Programme, ${ }^{9}$ which gives a structure to the implementation of Better Births, emphasises the importance of kind and personalised care, although postnatal care is not a specific work stream within this.

The need to invest in postnatal care arises from the knowledge that it is the most commonly criticised aspect of care by women, as evidenced in the National Maternity Survey reports and publications arising from secondary analysis of survey data. ${ }^{3} 1011$ However, we do not know if this is related to unmet expectations, poor experience of birth or afterwards, or the emotional and physical well-being of the women reporting their experiences.

As hospital postnatal stay has been decreasing in duration and also changing its focus, identifying changes in maternal expectations, experiences and satisfaction may provide important insights as to what aspects of care need to be improved for future services.

\section{Review objectives}

This review was conducted to inform a series of policy research projects on postnatal care in the UK. The main aim of this review was to comprehensively report on women's and families' expectations and experiences of the immediate postnatal care received in hospitals (including both alongside and free-standing birth centres). The following were the objectives:

- To report on women's satisfaction with hospital/birth centre postnatal care.

- To explore how this relates to expectations and experience of care.

- To identify gaps in hospital postnatal service provision in the UK.

\section{METHODS}

This review was reported according to the Preferred Reporting Items for Systematic Reviews and Meta-Analyses 2009 checklist $^{12}$ and registered with PROSPERO (see Postnatal Care Protocol V.6 in online supplementary file).

\section{Selection of studies and inclusion criteria}

Studies were eligible for inclusion if they involved women with low-risk pregnancies as defined by the National Institute for Health and Care Excellence (NICE) 2017 guidelines ${ }^{13}$ and gave birth in hospitals or birth centres in the UK. If studies contained data relating to both low-risk and high-risk pregnancies, only information relevant to the low-risk group was sought for inclusion. Studies conducted on women with high-risk pregnancies as defined by the NICE 2017 guidelines on antenatal care $^{13}$ were excluded. We initially planned to exclude studies involving women with various or unknown pregnancy risks, if it was not possible to separate data relating to low-risk women. Studies with findings relating to a woman's partner were also sought for inclusion. Studies of women of all ages, parity, ethnic background and mode of delivery were eligible for inclusion. Data were also sought regarding contextual information relevant to women's expectations, satisfaction and experiences of their immediate postnatal care in hospital or birth centre.

We incorporated findings from different research methods: qualitative, quantitative and mixed-method design studies. The quantitative studies of the following designs were eligible for inclusion: randomised controlled trials (RCTs), cross-sectional studies, retrospective or prospective survey-based studies, and observational cohort studies. As the aim was to provide an aggregative summary of what is known about women's experiences of hospital care, it was important to include all possible data in the synthesis. Qualitative studies included were interview studies, observational studies, focus groups studies and open-ended text from surveys where thematic analysis had been conducted. Surveys where free-text quotes were provided purely for illustrative purposes were excluded.

Reviews, editorials, commentaries and reports were only used to identify additional studies that were not retrieved by the searches. This review focuses on hospital postnatal care; thus, studies on aspects of community postnatal care were not included unless it was impossible to differentiate between them in which case they were included.

Any outcomes relevant to women's and families' expectations, experiences and satisfaction with postnatal care received in hospital or birth centres were extracted and are reported in this review.

\section{Search strategy and study selection}

The methodological component of the SPIDER (Sample, Phenomenon of Interest, Design, Evaluation, Research type $)^{14}$ search strategy was used. Sets of search terms were developed to cover the following concepts: expectations, experiences and satisfaction with postnatal care in hospital and birth centres in the UK. The MEDLINE 
search strategy is shown in online supplementary appendix 1 .

The following databases were electronically searched: Embase, MEDLINE, PsycINFO, Applied Social Sciences Index and Abstracts, Cumulative Index to Nursing and Allied Health (CINAHL Plus), Science Citation Index, and Social Sciences Citation Index. We also searched the grey literature in the databanks of British Library EThOS, OpenGrey and ProQuest Dissertations \& Theses Global. All retrieved references were stored in EndNote (V.X8) and screened independently by the review authors.

We restricted our search to English language only and limited by date from 1970. This date was chosen as many changes to postnatal care policies took place subsequently. Review searches were conducted in February 2017. An update search was carried out in February 2019. Authors were contacted as necessary to locate full-text papers.

\section{Assessment of the included studies}

For quantitative designs we applied a modified version of the National Institutes of Health Quality Assessment Tool for the observational cohort and cross-sectional studies. ${ }^{15}$ This tool was used to assess included studies for generalisability and risk of bias based on recruitment, exclusion criteria applied, description of the study population (demographic, location and time period), sample size, response rate and comparability with the wider population. The tool also assessed the adequacy of statistical techniques and adjustment for potential confounders and the reliability and validity of standardised measures. We rated the quality of evidence on each domain as 'yes' for low risk of bias, 'no' for high risk of bias and 'unclear' when no information was provided to support the judgement. The Critical Appraisal Skills Programme (CASP) risk of bias tool for $\mathrm{RCTs}^{16}$ was implemented to rate the quality of any RCTs identified for inclusion in this review.

For evaluating the risk of bias of qualitative studies, we used the CASP. ${ }^{16}$ This tool has a checklist of 10 questions which cover the study objectives and rationale, study methods, study design, recruitment strategies, method of data collection, information on ethical approval, and rigour of the method of analysing data and reporting of findings. Each domain is designated 'yes', 'no' or 'unclear' as above.

For mixed-methods studies, the quantitative and qualitative components were assessed and reported separately, and are thus included in both quantitative and qualitative tables.

All reviewers independently assessed the quality of the included studies, and any discrepancies in quality rating were resolved by discussion.

\section{Data extraction and data analysis}

We designed two different data extraction forms, one for the quantitative studies and the second for the qualitative studies. We extracted information relevant to participants' characteristics, study period, setting, study objective and study specified outcomes, in addition to the summary of results. Data from mixed-method studies were entered in both the qualitative and quantitative forms as appropriate. No authors were contacted to seek additional information. In this review we report findings from qualitative and quantitative studies separately. Meta-analyses were explored for quantitative data; however, heterogeneity was greater than $90 \%$ so this was not appropriate. Forest plots have been provided for outcomes where the variables were similar. An aggregative synthesis approach was used to summarise the qualitative data. With this approach the concepts are assumed to be largely well specified ${ }^{17}$ and the data pooled by providing a descriptive account of the pooled data.

We planned to perform the following subgroup analyses using both quantitative and qualitative data:

- By parity.

- By mode of delivery.

- Ethnicity.

- By the duration of postnatal stay: <24hours, $24<48$ hours, $48<72$ hours, $>72$ hours.

- Postnatal care received in hospitals in comparison with birth centres.

- Comparisons over time: 1970-1989, 1990-2009 and 2010 to present.

\section{Patient and public involvement}

The need for a broad review of postnatal care was identified through discussion with our stakeholder groups, which included discussion with our parent, patient and public involvement (PPPI) stakeholders network. Dissemination of findings to stakeholders will be through plain language summaries developed with members of our PPPI stakeholders network.

\section{RESULTS}

\section{Results of the search}

The search strategy retrieved 3118 references, of which 759 were duplicates and were removed. An additional 12 references were identified through hand searching of the reference list of full-text studies. Overall, 2371 titles and abstracts were independently screened by at least two reviewers, resulting in 151 full texts being retrieved. These were assessed for eligibility, and 53 studies are included in this review. Of these, 28 studies were purely quantitative, 19 purely qualitative and 6 used mixed methods (figure 1).

\section{Description of included studies}

Summaries of the included studies are presented in tables 1 and 2 for quantitative and qualitative studies, respectively.

\section{Quantitative studies}

There were 34 quantitative studies included in the review, ${ }^{13101118-46}$ of which 6 were mixed methods. ${ }^{222428333740}$

Of these studies, two were RCTs, ${ }^{32} 40$ one was a non-randomised controlled study, ${ }^{36}$ a further study 


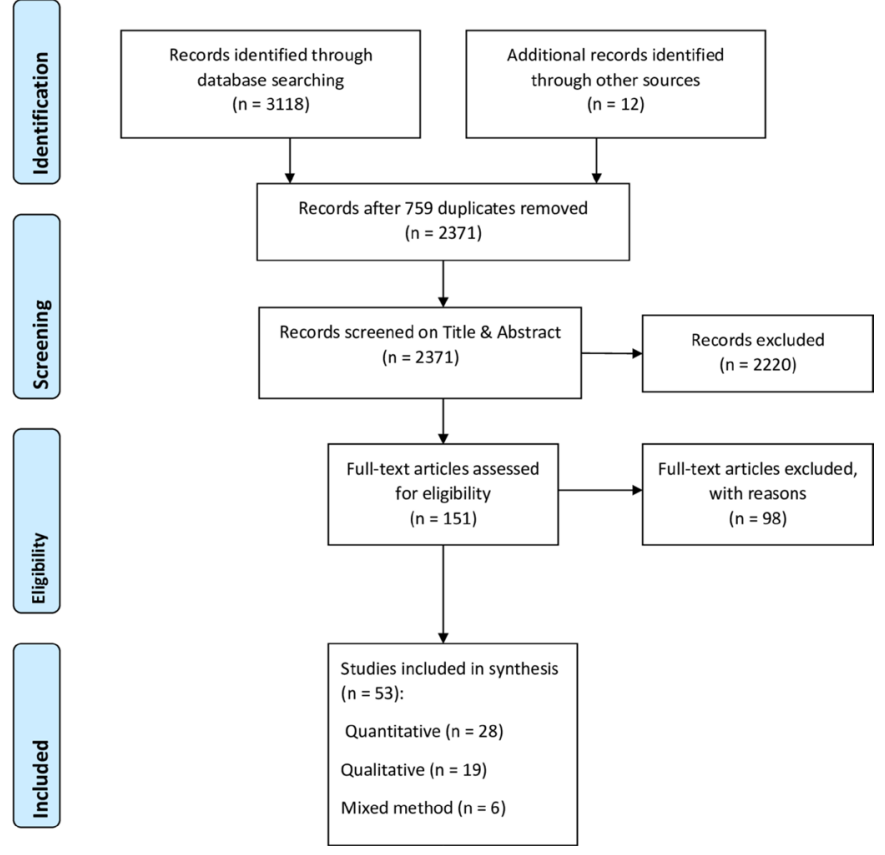

Figure 1 PRISMA 2009 flow diagram. PRISMA, Preferred Reporting Items for Systematic Reviews and Meta-Analyses.

was a before-after intervention study, ${ }^{19}$ and another three ${ }^{33374}$ were cohort studies. The remaining 27 studies were cross-sectional surveys, 20 of which were national surveys with sample sizes ranging from $1137^{34}$ to $26325 .^{30}$ Survey questions asked women their views on interpersonal and communication aspects of care, infant feeding advice and support received, physical and emotional wellbeing, length of stay and their view of their length of stay, and overall satisfaction.

The aim of the two included RCTs ${ }^{32} 40$ was ultimately to compare standard maternity care with midwife-led and managed care. Hicks et $a l^{32}$ was a pilot study aiming to explore the compatibility of a new maternity care framework with maternity care as envisaged by the Changing Childbirth project. Women were randomised to either an experimental continuity of care group or a traditional care group. Women's satisfaction with a variety of aspects of care was recorded. These included information received and interaction with healthcare professionals. In the second RCT, ${ }^{40}$ women were randomised to midwife-managed care or to standard care. However, looking at interventions to improve hospital postnatal care was not the intention of our review. Only data on women's satisfaction ratings with the interaction with healthcare professionals, information transfer, choices and decisions, and social support were collected.

Of the included studies, 13 were conducted before 2000, ${ }^{26-29} 3334363740-4345$ and 21 were conducted since then. The majority of the studies were conducted in England, but one was conducted in Northern Ireland ${ }^{18}$ and seven in Scotland. 24252934394042
Risk of bias of included studies

The methodological quality of the included studies was overall moderate to low (table 3 ). The study objectives were clearly prespecified in most of the included studies, but the research question was unclear in 11 studies. $^{3} 10$ 21-25 28303540 All the studies except one ${ }^{35}$ involved predefined populations. Of the 33 studies using surveys, 25 had response rates of at least $50 \%$, and of those 8 studies had response rates over $70 \%$, 2627293233364345 although in 1 study the denominator was women who had already agreed to participate. ${ }^{29}$ However, response rates were not reported and not possible to calculate in two studies. ${ }^{35} 46$ Sample selection was not clearly reported across the included studies, and in the majority of the studies the population had mixed risk status rather than low risk. The generalisability of the study results was also limited by differential response rates with significantly fewer responses from young, single women, those born outside the UK and those residents in deprived areas. Most of the studies reported methods to check the validity and reliability of the surveys. Overall, most of the included studies involved a sample size greater than 100 and used reliable and valid outcomes measures. However, few studies adjusted for potential confounding factors, ${ }^{31931323846}$ or used statistical weighting to adjust for differential response rates. ${ }^{20-2530}$

We assessed the methodological quality of the two RCTs identified for inclusion using the CASP risk of bias tool for RCTs. Both RCTs ${ }^{32} 40$ clearly stated the focus of their research. Allocation to interventions was assigned randomly and the randomisation methods were reported in both trials. Information regarding whether women were aware or blinded to the intervention status is missing. Both trials reported no significant differences between groups at baseline. However, information relating to whether the groups were treated equally or differently during the study duration was unclear in both trials. Outcomes of interest were aspects of women's satisfaction with the care they received, and as these were self-reported by the women themselves we are unable to discount the existence of bias in measuring outcomes. With regard to the intervention effect estimates, in Hicks et $a l^{32}$ women reported a similar level of care satisfaction. In Shield et $a l,{ }^{40}$ the estimated satisfaction with care was significantly higher in the midwife-managed care in comparison with the shared care group in relationships with staff, information transfer, choices and decisions and social support. Data on women's emotional and physical support were not collected in either trial.

\section{Quantitative results}

Findings are reported by outcomes described across the included papers. Combining data for the following outcomes resulted in a significant heterogeneity across the study $\left(\mathrm{I}^{2}>90 \%\right)$ (meta-analyses not shown). Therefore, findings were tabulated and displayed in forest plots where possible. 


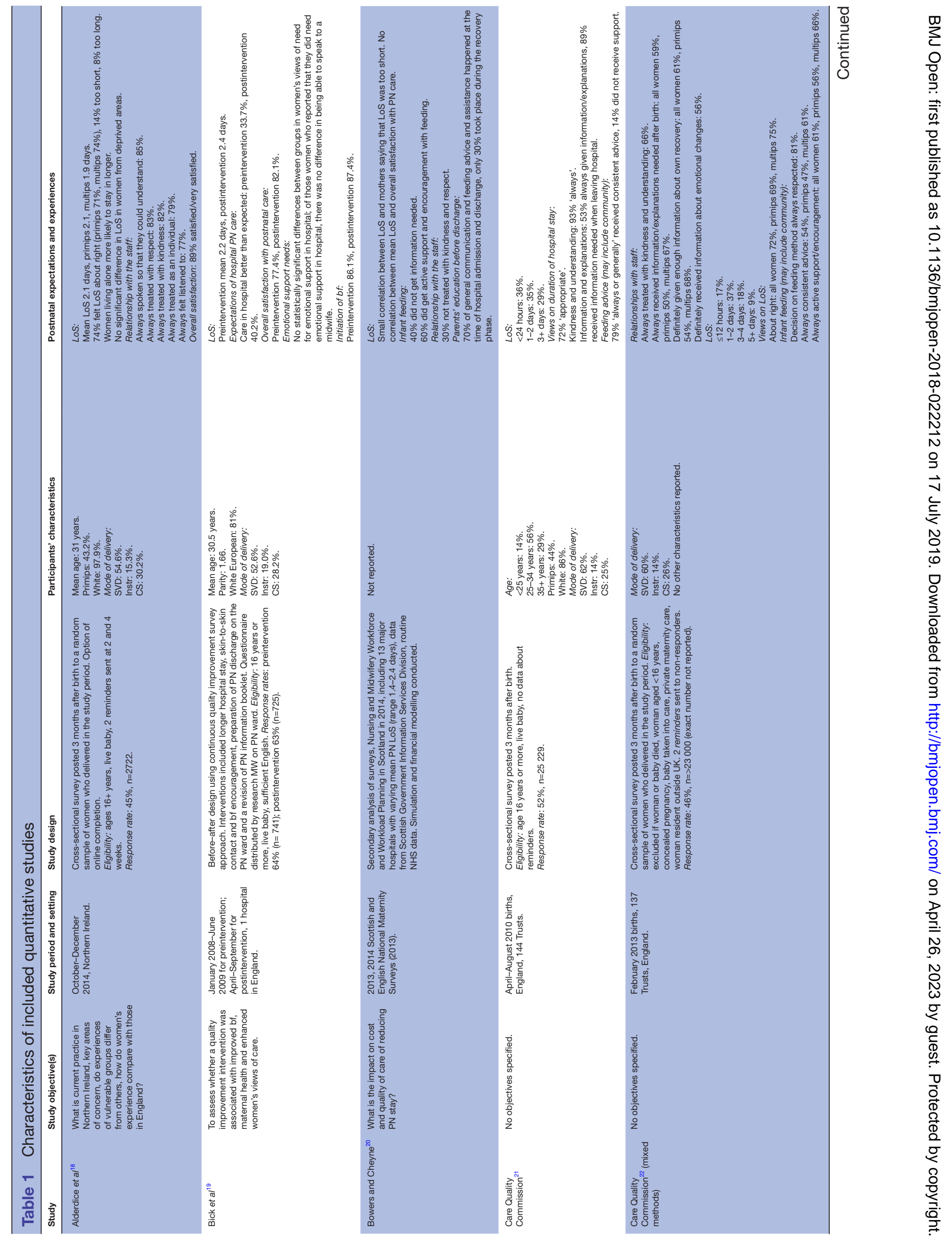




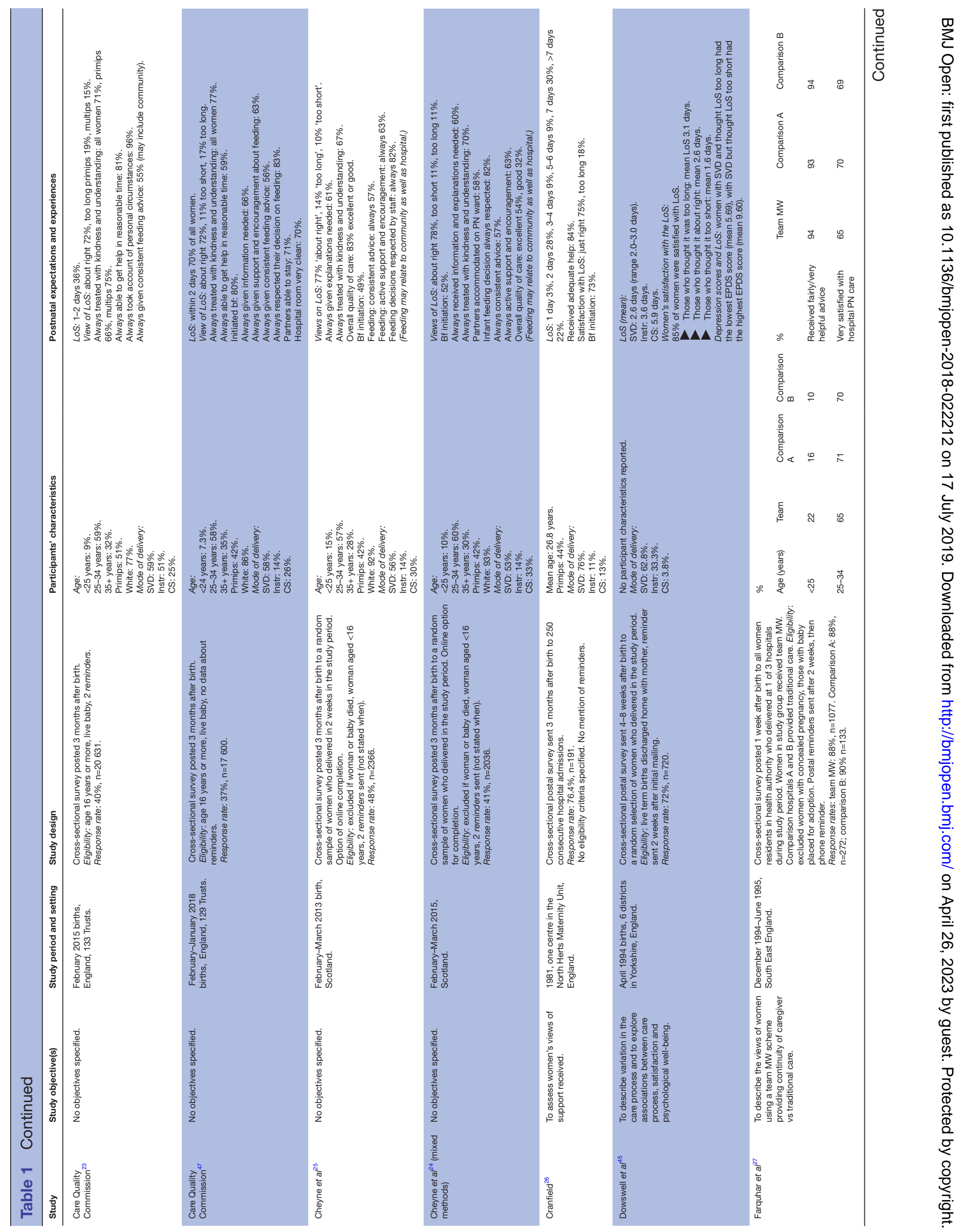




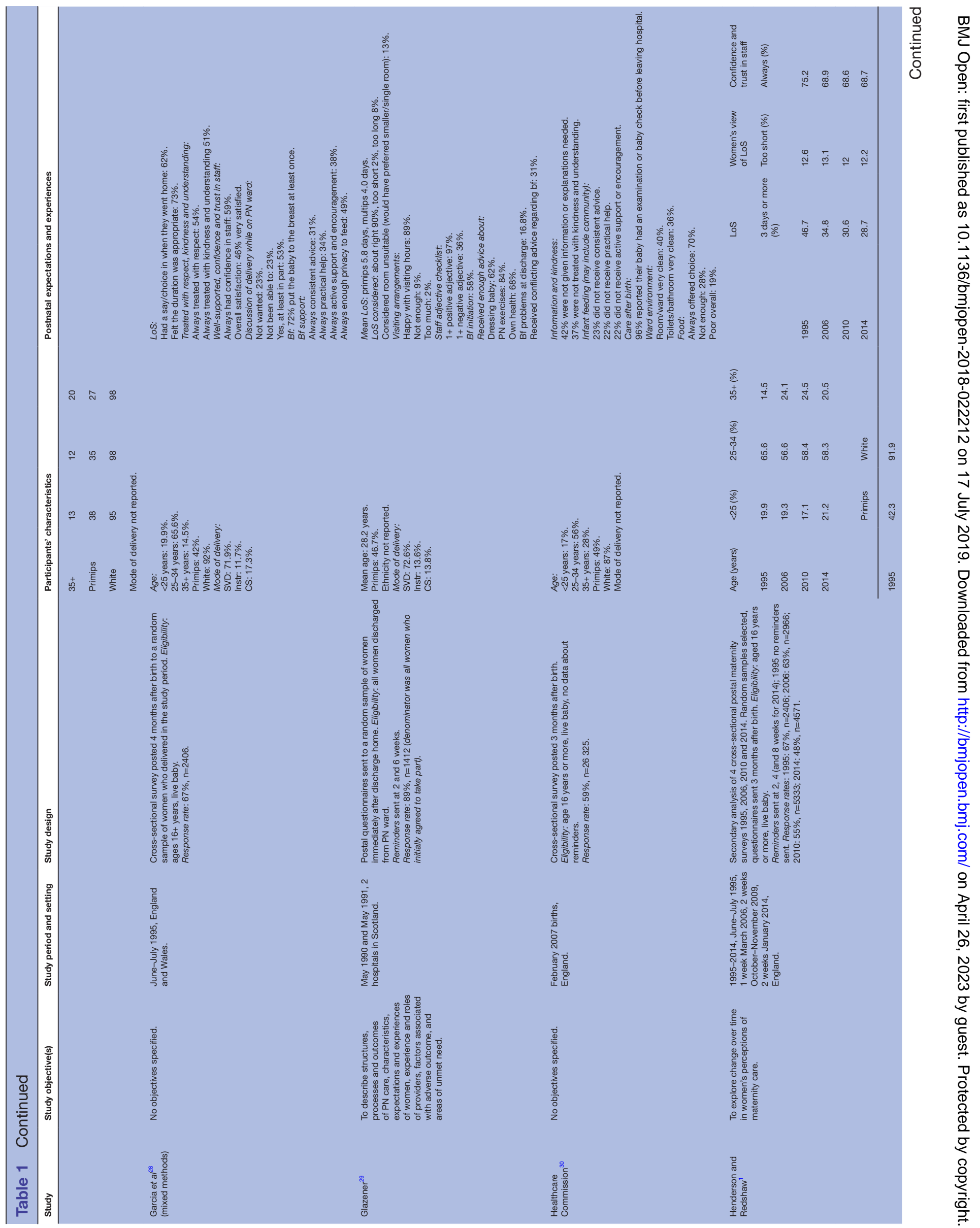




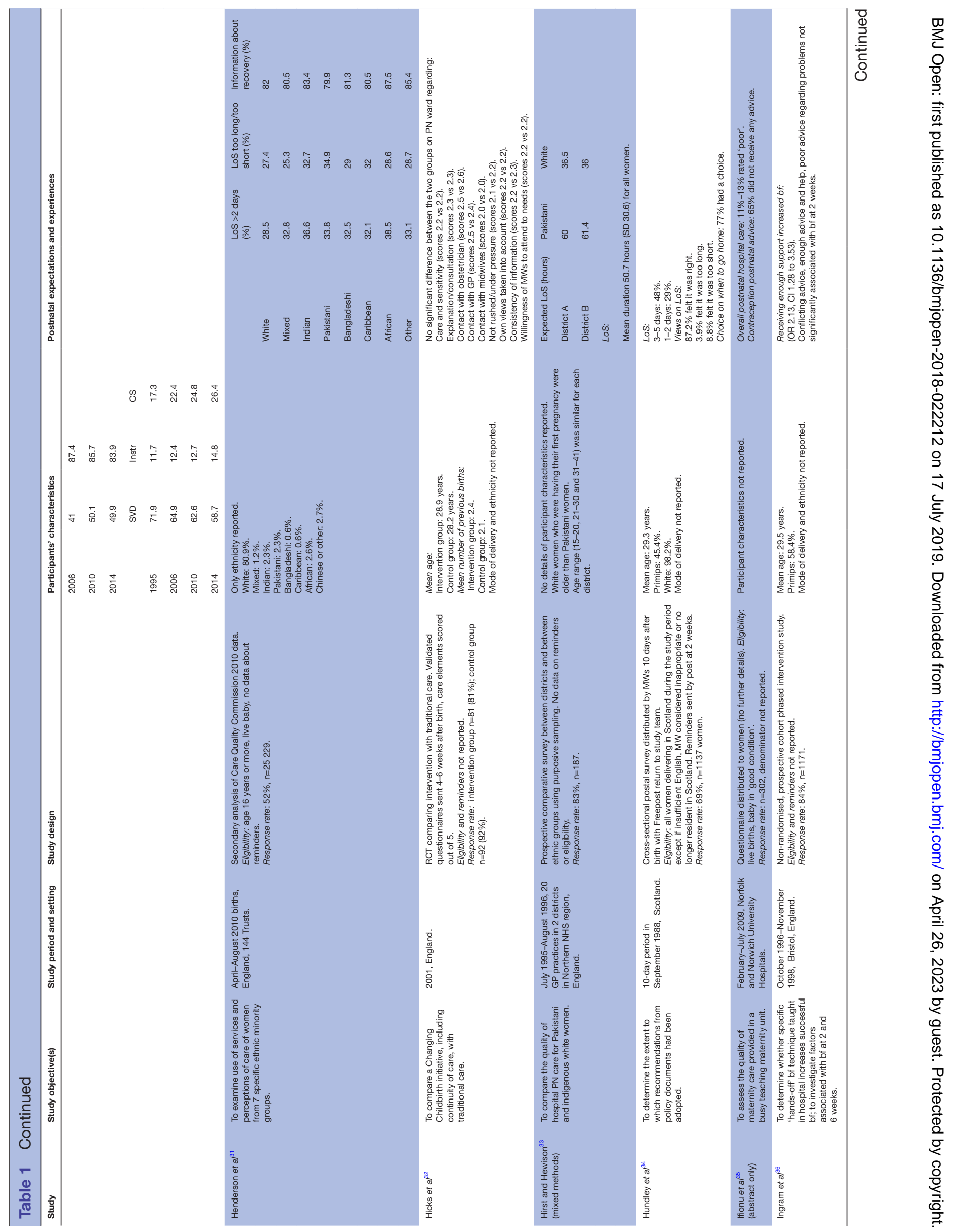




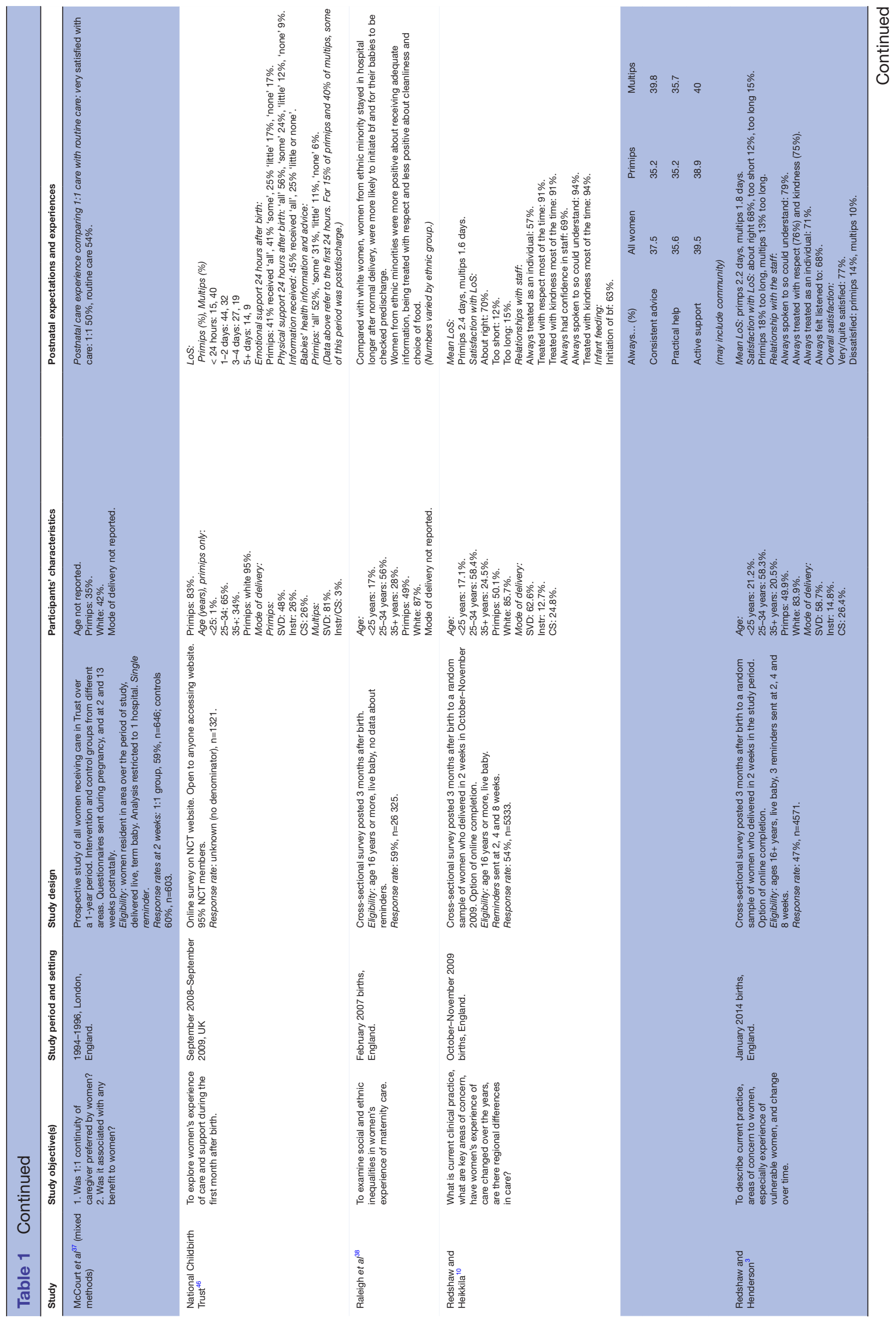

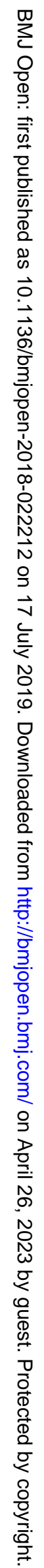




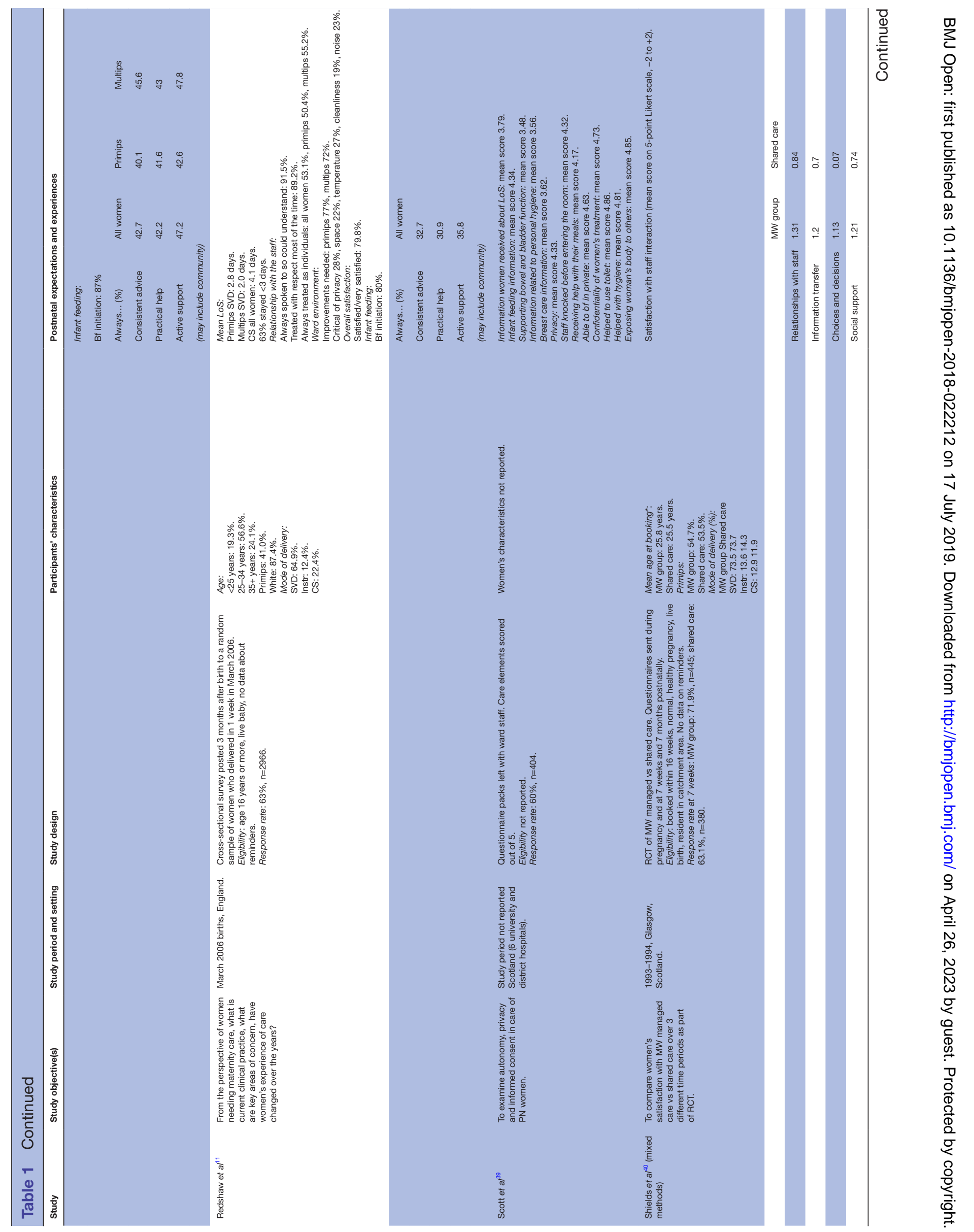




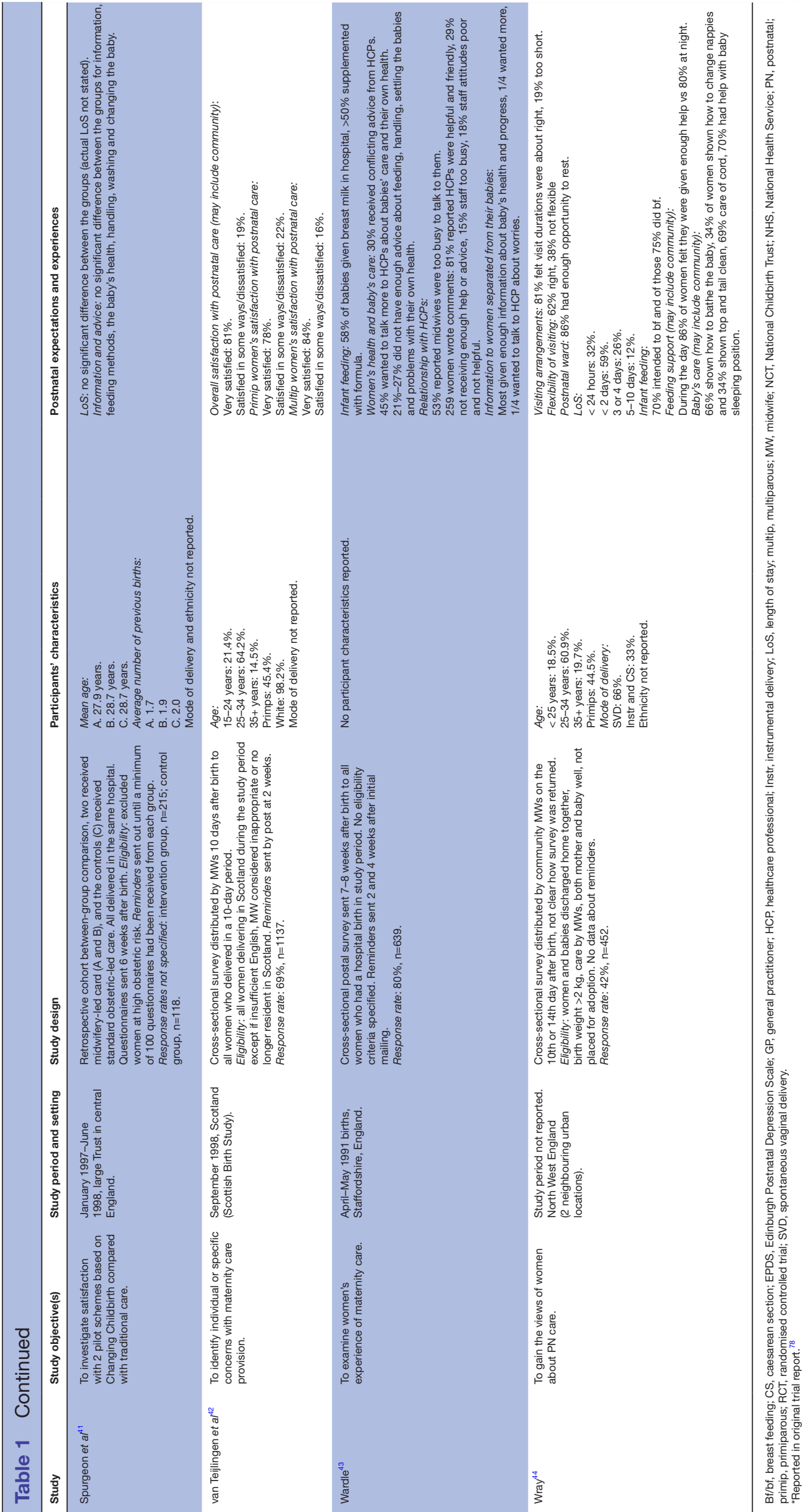

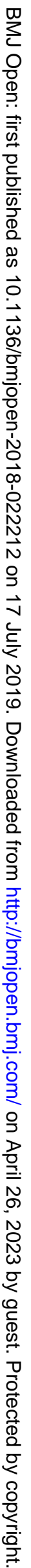




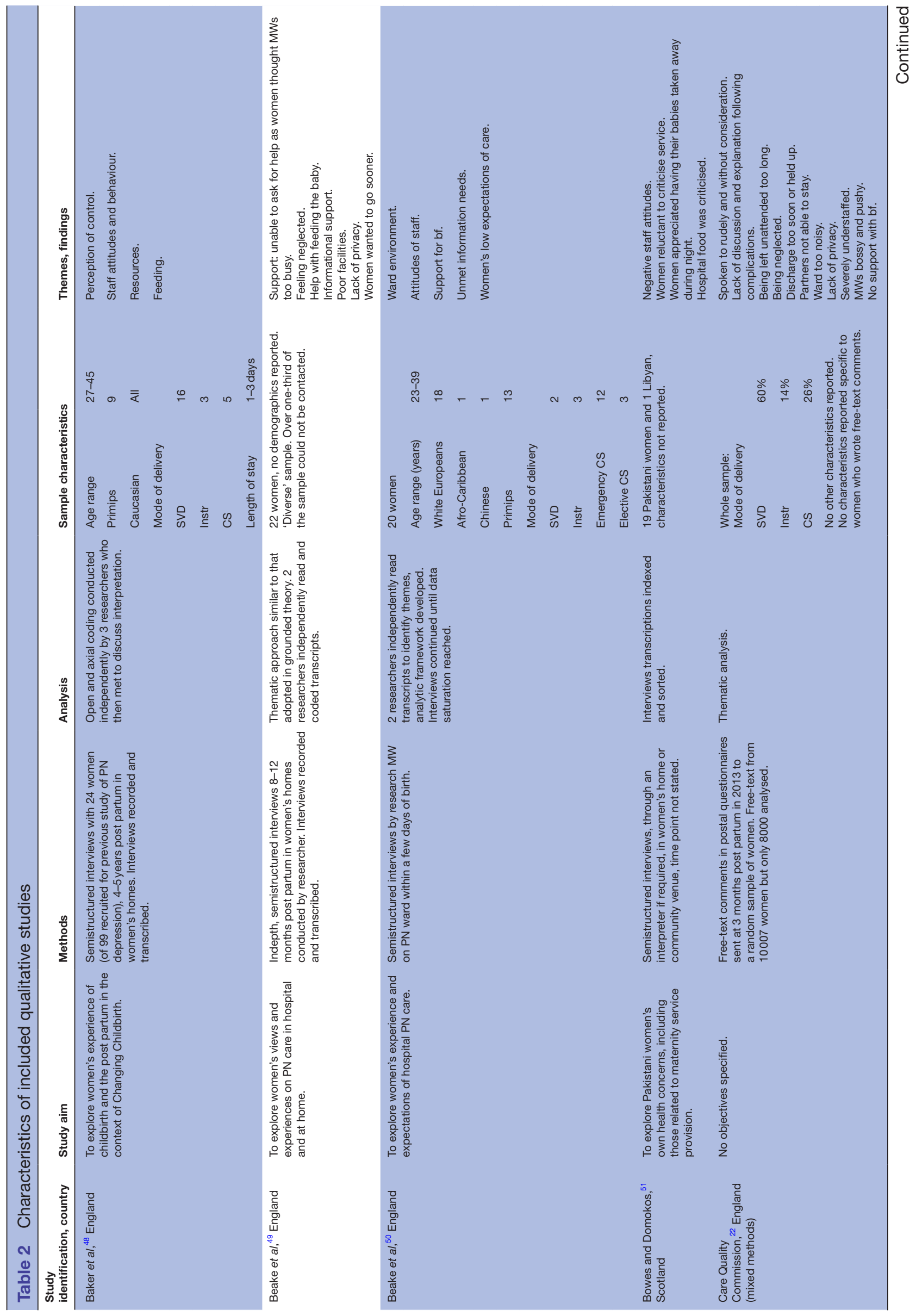

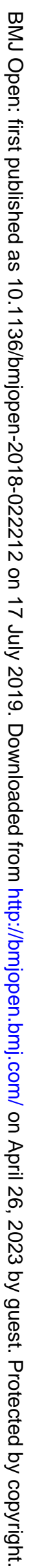




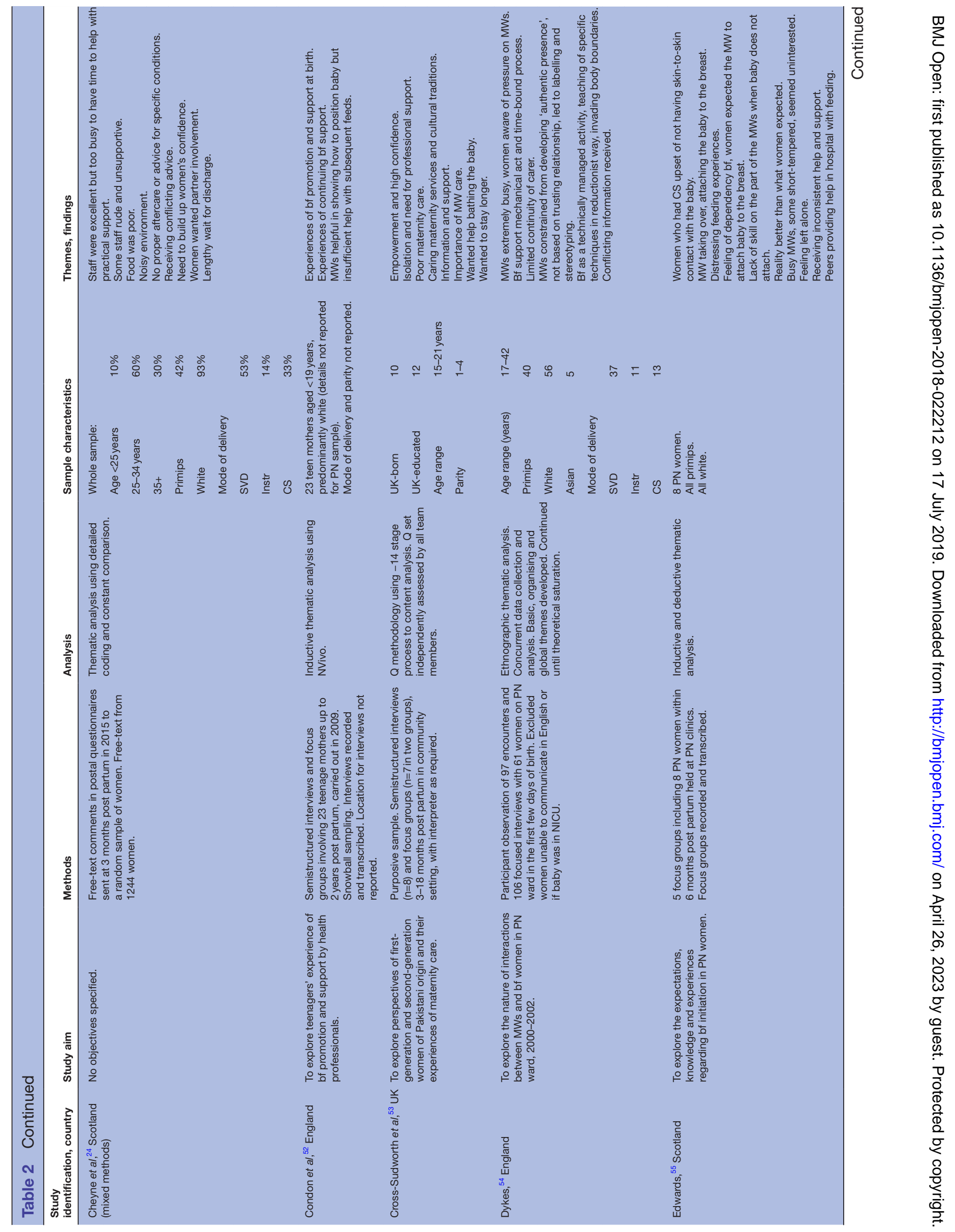




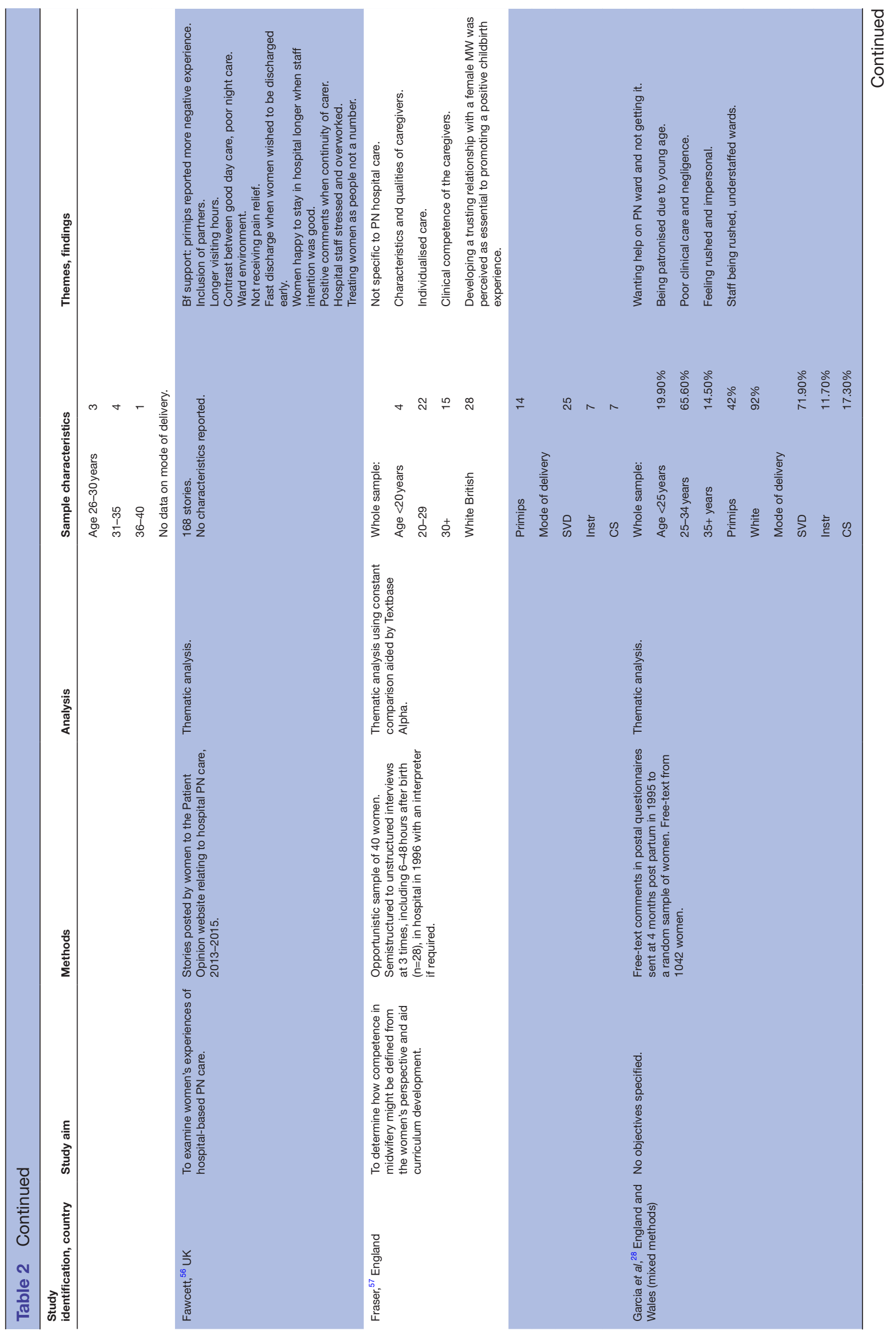

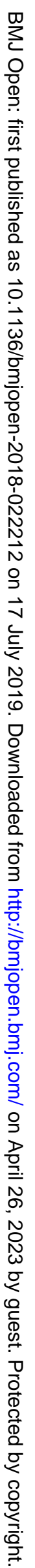




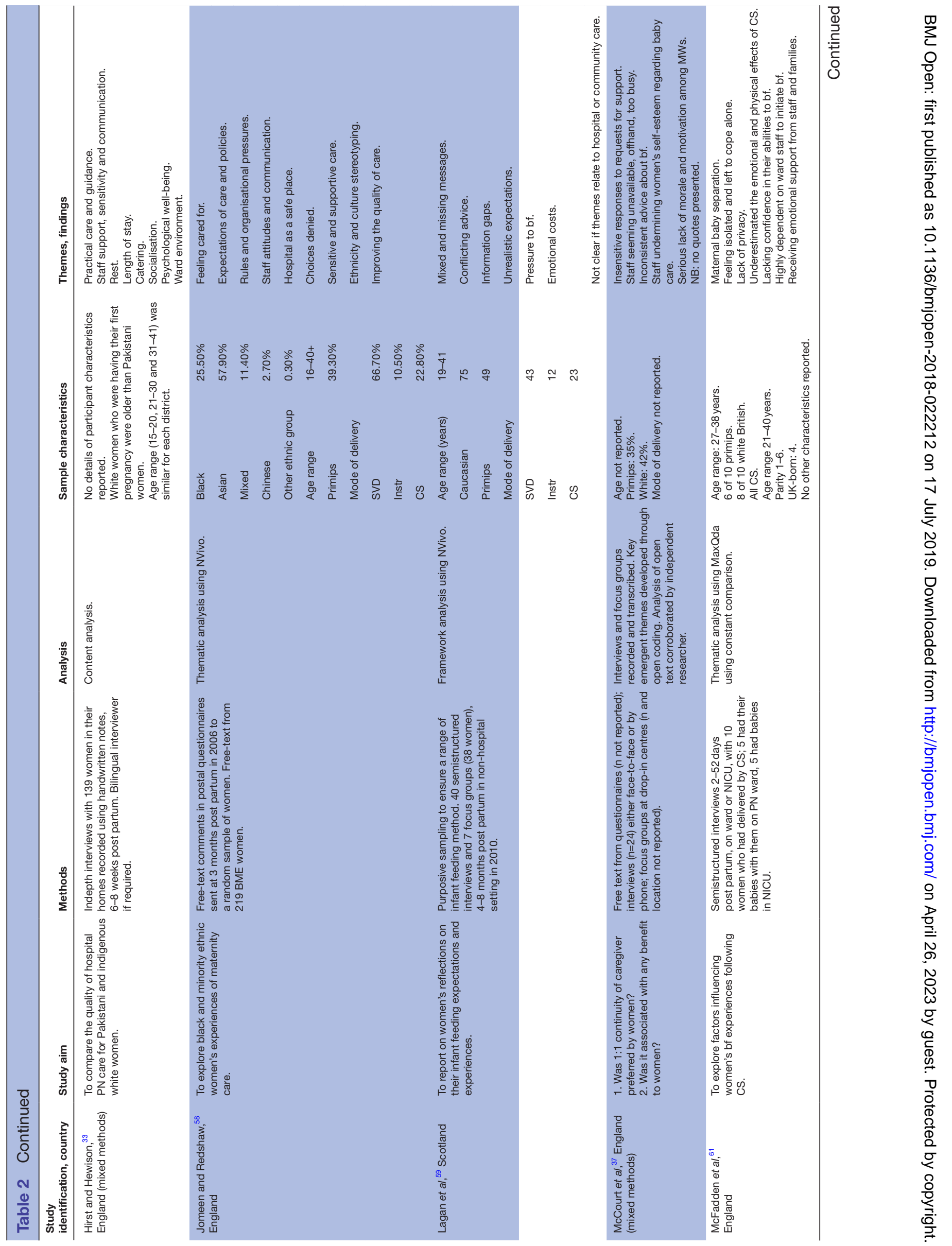




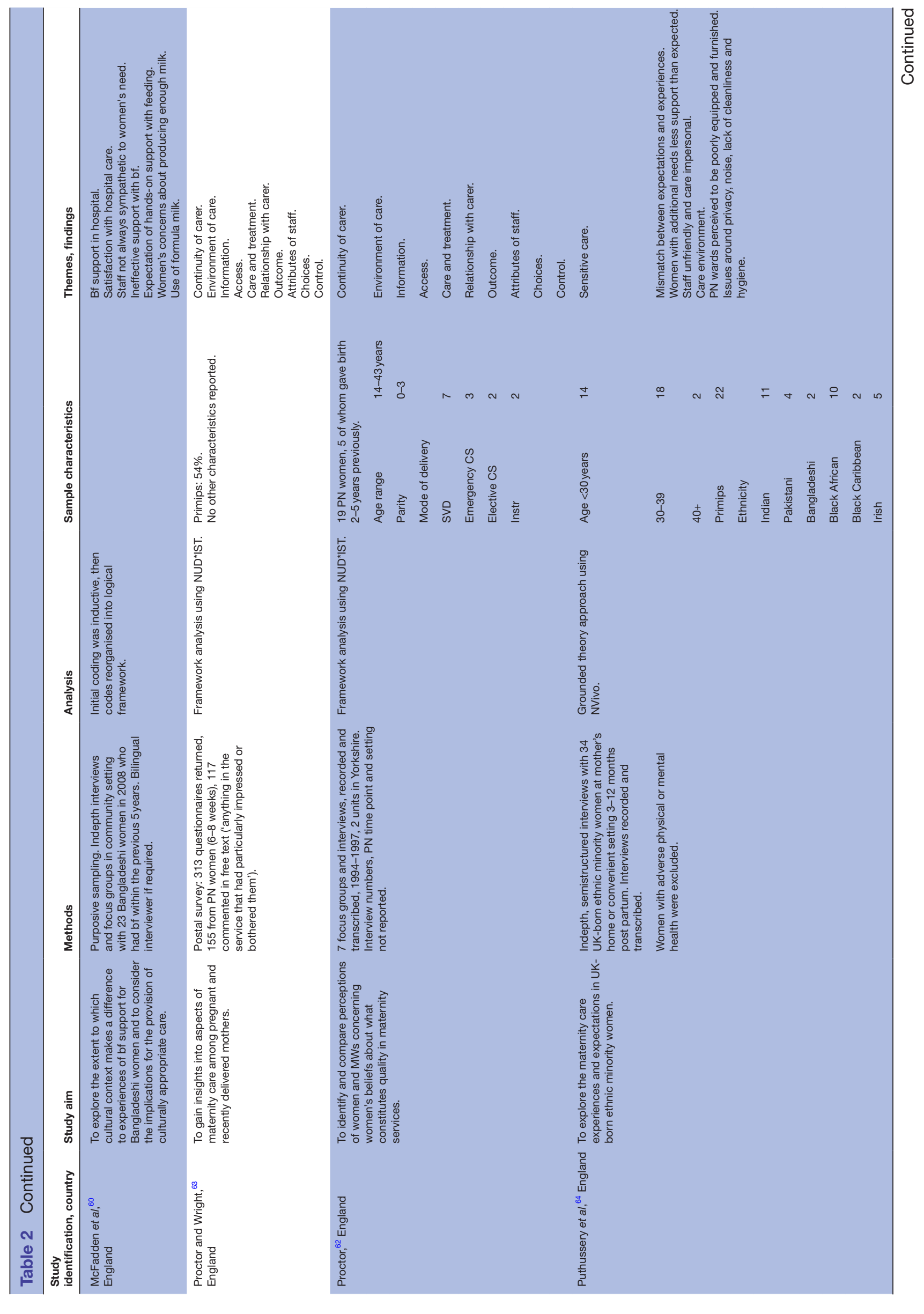

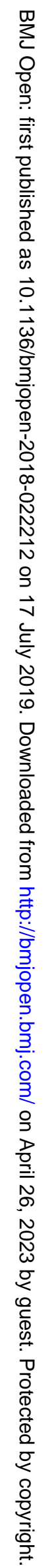




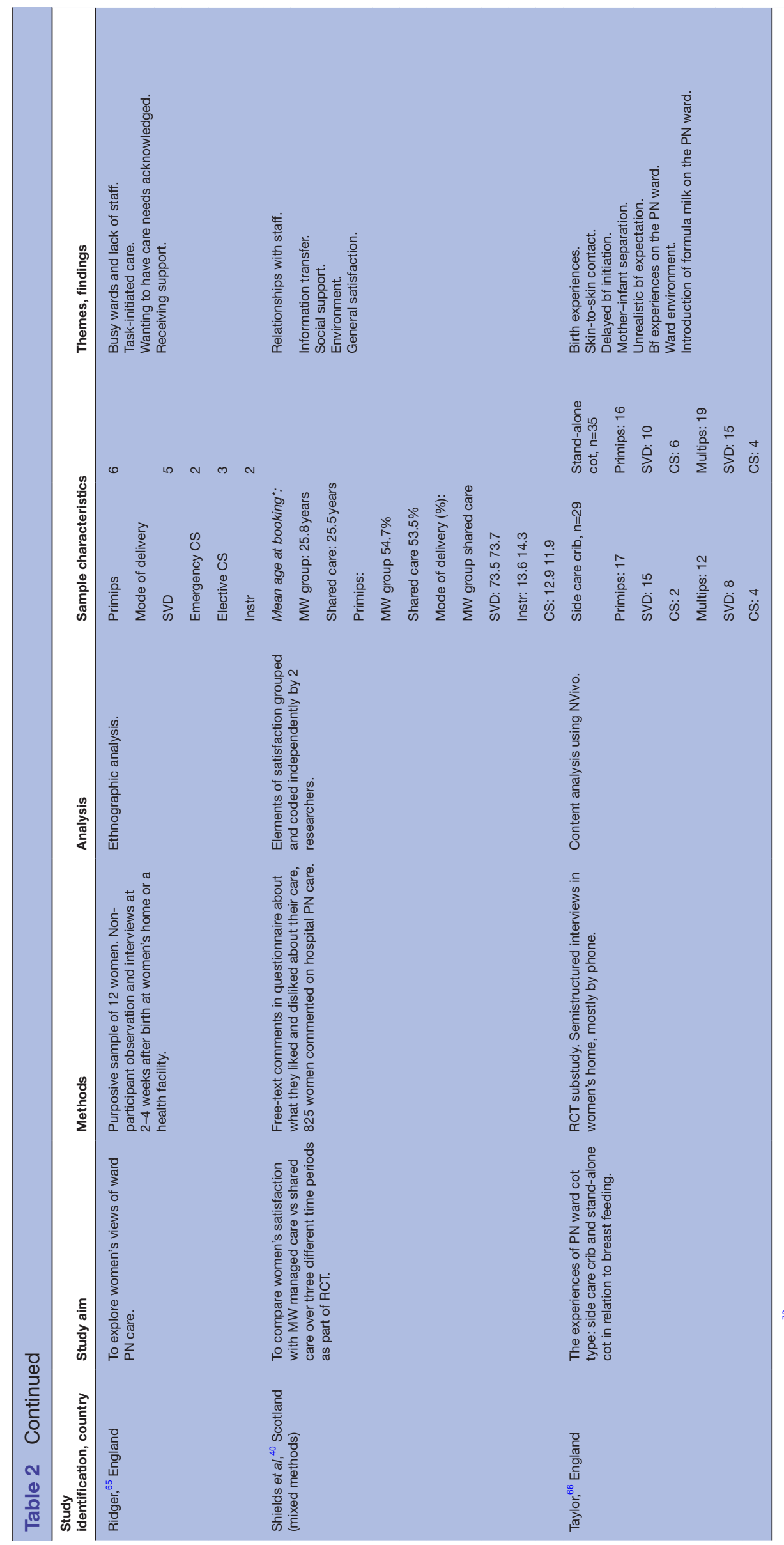

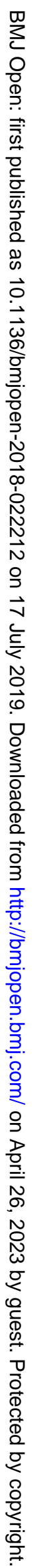




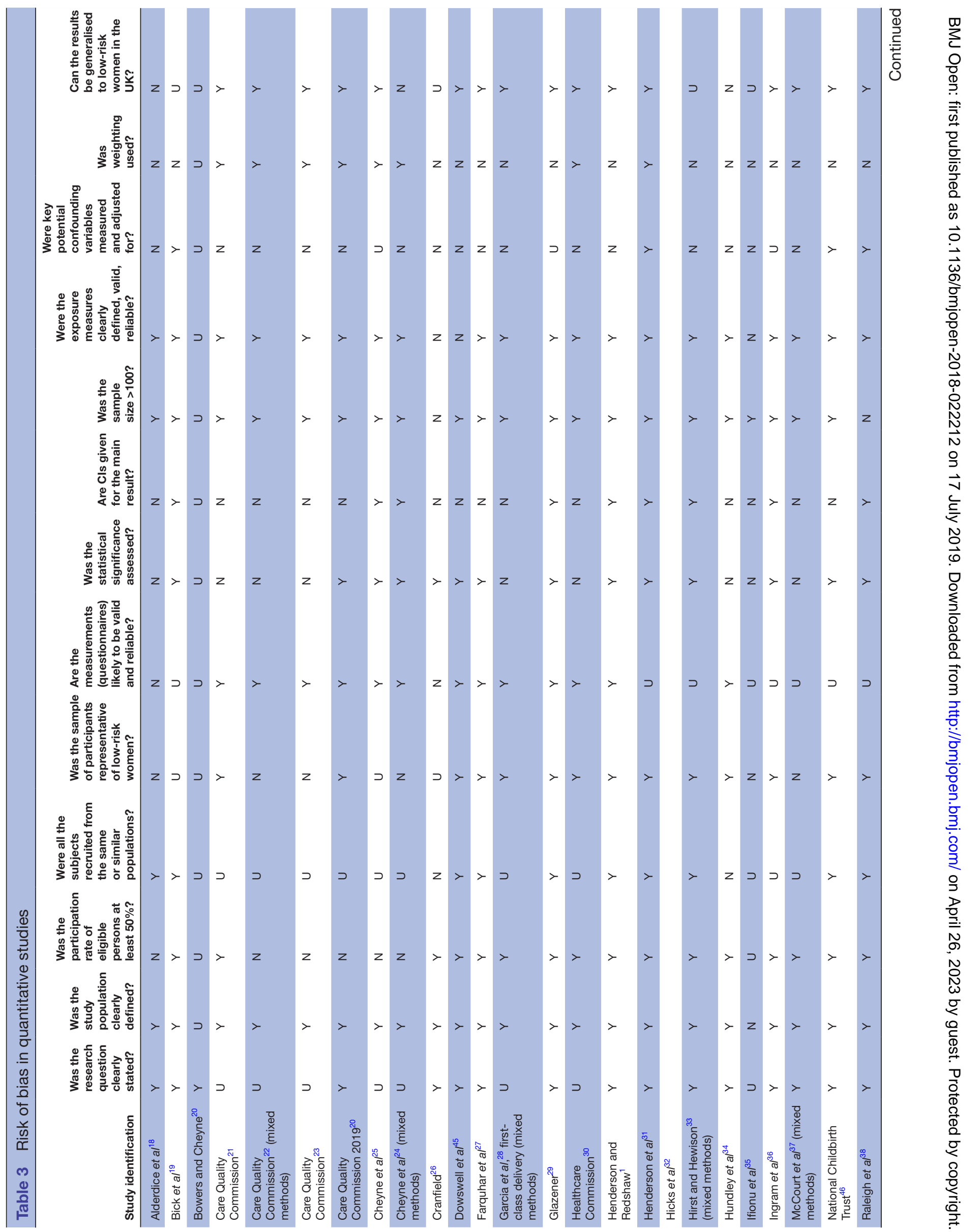




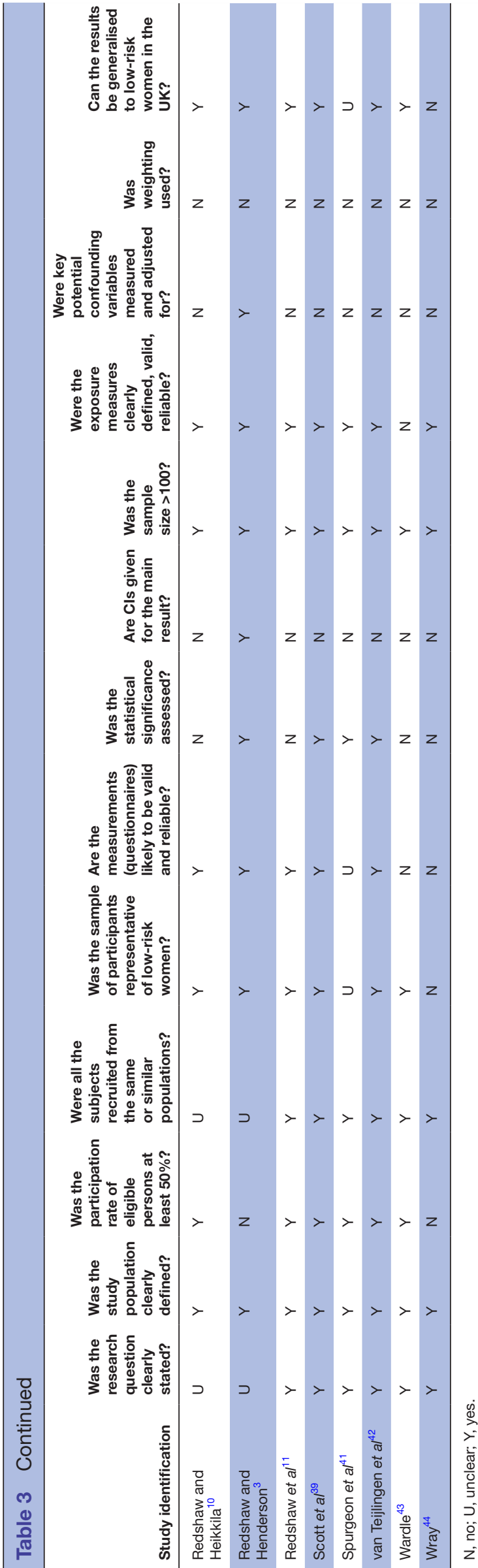

Women's expectations of hospital postnatal care

Women's expectations of care were reported in one study only. ${ }^{19}$ This was a continuous quality improvement study with a before-after design. Prior to the intervention, $33.7 \%$ of women reported that care in hospital after birth was better than their expectations, and after the intervention this increased to $40.2 \%$.

\section{Interaction with healthcare professionals}

Almost all the studies in this section of the review included some discussion of staff attitudes, communication and/or practical help received. ${ }^{1} 31011$ 18-32 35 38-41 43444647 However, different studies asked different questions in various different ways, making comparison problematic.

Adequate practical help was reportedly received by $84 \%$ of women in one study, ${ }^{26}$ and $59 \%$ always received help in a reasonable time. ${ }^{47}$ In another study, $56 \%$ of primiparous women reported receiving all necessary physical support. ${ }^{46}$ Between $79 \%{ }^{3}$ and $94 \%{ }^{10}$ of women were always spoken to so that they could understand, but only $47 \%$ of women reported that they had enough time to talk to midwives. ${ }^{43}$ Between $54 \%$ and $83 \%^{318}{ }^{28}$ were always treated with respect, and 91\%-92\% were mostly treated with respect. ${ }^{10}{ }^{11}$ Two surveys reported that $68 \%$ and $77 \%$ of women felt listened to. ${ }^{3} 18$ Four surveys also reported women's perceptions of always being treated as an individual on the postnatal ward at between 53\% and $79 \%$. $^{3} 101118$

Kindness, understanding and sensitivity were reported more widely. ${ }^{31011} 1821-2528303247$ Between 51\% and 93\% of women reported always being treated with kindness, but in a further survey only $41 \%$ of primiparous women received all necessary emotional support. ${ }^{46}$ Care and sensitivity were also reported as a score, 2.2 out of $5,{ }^{32}$ and on a scale of -2 to +2 social support scored between 0.7 and 1.2. ${ }^{40}$ Always having confidence and trust in staff on the postnatal ward was reported in two studies at $59 \%$ and $69 \% .^{1028}$

\section{Information}

Another vital aspect of postnatal care is for women to receive clear and adequate information. This was reported in 11 studies. $^{21} 22242527303240434647$ Adequate information and explanations were always received by $53 \%, 58 \%$ and $65 \%$ of women in three surveys ${ }^{21} 3047$ compared with 93\%-94\% who received fairly or very helpful advice in another study. ${ }^{27}$ The two studies which used the scoring systems referred to above reported explanations at 2.3 out of $5^{32}$ and information transfer at between 0.7 and 1.2 on a -2 to +2 scale. ${ }^{40}$ Information about specific elements of care such as the woman's recovery, postnatal exercises, emotional changes and advice about baby care was reported more patchily. Between $61 \%^{22}$ and $88 \%{ }^{31}$ of women were given information about their recovery, $84 \%$ about postnatal exercises, ${ }^{29} 53 \%-56 \%$ about emotional changes ${ }^{22}{ }^{27}$ and between one-third and three-quarters of women reported receiving information about elements of baby care. ${ }^{29} 434446$ 


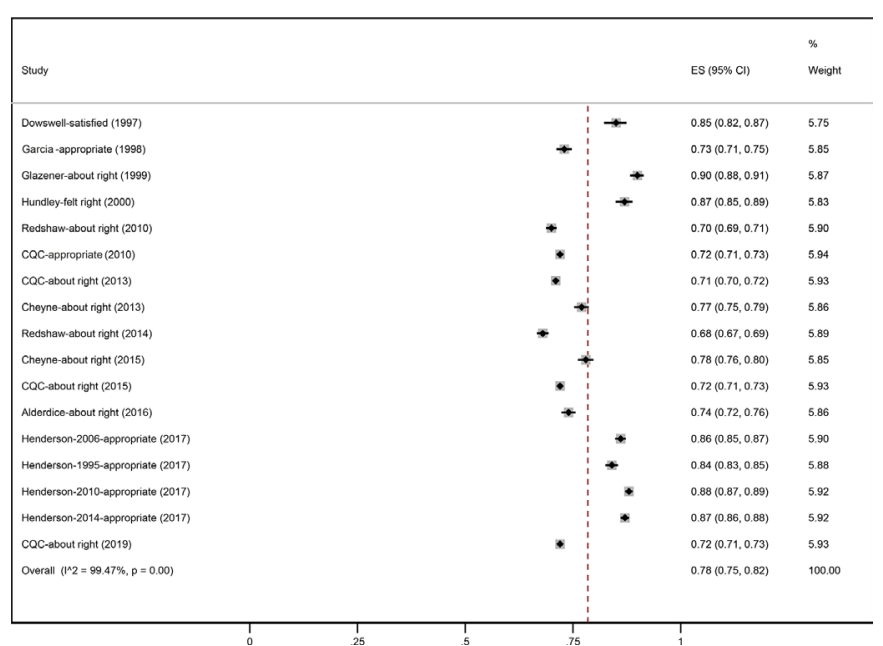

Figure 2 Proportion of women who were satisfied with length of postnatal hospital stay. CQC, Care Quality Commission; ES, effect size.

\section{Postnatal hospital stay}

More than half of the studies reported on the duration of hospital stay and/or women's views about their length of stay. ${ }^{1} 310111819$ 21-2628 293133 34 44-46 The mean length of stay was stated in seven studies ${ }^{1011} 1819293345$ and ranged from 1.8 days in multiparous women in $1990^{29}$ to 5.9 days in women following a caesarean delivery in $1994 .{ }^{45}$ The proportion of women with longer lengths of stay declined over the years, and this is described below under the Subgroup analyses section.

About three-quarters of women felt that their duration of stay was about right. ${ }^{110} 1819212224-262829313445$ The proportion of women who felt satisfied with the length of hospital postnatal stay is visually presented in forest plots (see figure 2). The proportion of women who considered their length of stay too short remained remarkably constant over time at $12 \%-13 \%{ }^{1}$ Two studies reported that $62 \%$ and $77 \%$ of women, respectively, had some choice in their duration of stay. ${ }^{28} 34$ Another study reported that there was an association between women considering their length of stay too short and scoring high on the Edinburgh Postnatal Depression Scale. ${ }^{45}$ However, no correlation was found between length of stay and overall satisfaction with postnatal care. ${ }^{20}$

\section{Infant feeding}

Data relating to infant feeding were reported in more than half of the studies. ${ }^{3} 1011$ 18-26 28-30363839434447 The proportion of women who reported initiating breast feeding ranged from $49 \%$ in Scotland in $2013^{25}$ to $87 \%$ in England in 2015. ${ }^{3}$ Infant feeding support was also reported in 15 studies. ${ }^{3} 101118$ 20-26 28-30 39 Consistent advice in relation to infant feeding was always received by between $31 \%^{28}$ and $77 \%$ of women, ${ }^{30}$ although most estimates were between $40 \%$ and $60 \%$. Women were also asked in most of the national surveys if they received practical help with infant feeding. Between $31 \%^{1128}$ and $46 \%{ }^{18}$ of women reported that they always received practical help. Similarly, always receiving support and encouragement ranged from $38 \%{ }^{28}$ to $78 \% .^{30}$ Three studies reported that infant feeding decisions were always respected in $81 \%-82 \%$ of cases, ${ }^{21} 2425$ but always having privacy to breast feed was reported by only $49 \%$ of women in one study. ${ }^{28}$

Apart from problems of definition and timing, many of these studies did not differentiate between feeding support in hospital and at home. However, a study which focused specifically on breastfeeding support in hospital ${ }^{36}$ reported that receiving enough support was associated with an adjusted OR of 2.13 (95\% CI 1.28 to 3.53) for successful breast feeding.

\section{Ward environment}

Six studies reported women's views of the ward environment, ${ }^{11} 2930394447$ including aspects of visiting, partner being able to stay and ward hygiene. Three studies reported women's views of visiting: $81 \%-89 \%$ of women were happy with the visiting arrangement, but $9 \%-19 \%$ thought visiting was too short, $2 \%$ thought too much visiting was allowed, and 38\% thought it insufficiently flexible. ${ }^{294}$ In the most recent study, ${ }^{47} 22 \%$ felt restricted by visiting hours. However, $71 \%$ said their partners were able to stay with them. One study reported partners' experience of postnatal care and the impact of partners' presence on women's experience. ${ }^{24}$ In that study $58 \%$ of partners were accommodated on the postnatal ward; however, their experience in this regard was not reported.

Ward hygiene, particularly in the toilets and bathrooms, was a concern for many women, being reported as very clean by only $46 \%$ in one study ${ }^{29} 30$ and $19 \%$ in another. ${ }^{11}$ However, this may have improved: in the most recent Care Quality Commission survey, $70 \%$ of women reported wards as being 'very clean'. Women were also critical of food, ${ }^{30}$ privacy, space, temperature and noise levels. ${ }^{11}$

\section{Overall satisfaction with hospital postnatal care}

Eight studies reported women's overall satisfaction with hospital postnatal care,, 310111927283742 and three others reported overall quality of postnatal care. ${ }^{24} 2535$ About three-quarters of women reported being satisfied or very satisfied with care, ${ }^{3101119}$ and between $46 \%$ and $81 \%$ reported being very satisfied with care 283742 ; however, the figure of $81 \%^{42}$ was from a survey distributed by midwives at 10 days post partum so may be biased. Good or excellent quality postnatal care was reported by $83 \%-86 \%$ of women in two Scottish surveys, ${ }^{24}{ }^{25}$ and as poor by $11 \%-13 \%$ of women in another study. ${ }^{35}$ Forest plots of the proportion of women who were satisfied with overall postnatal hospital care are presented in figure 3.

\section{Qualitative studies}

The literature search and screening resulted in 19 purely qualitative studies and 6 mixed-methods studies that included qualitative data relating to hospital postnatal care. ${ }^{22} 242833374048-66$ Of these 25, 17 were based on interviews, ${ }^{28} 3337$ 48-54 57-78 7 on focus 


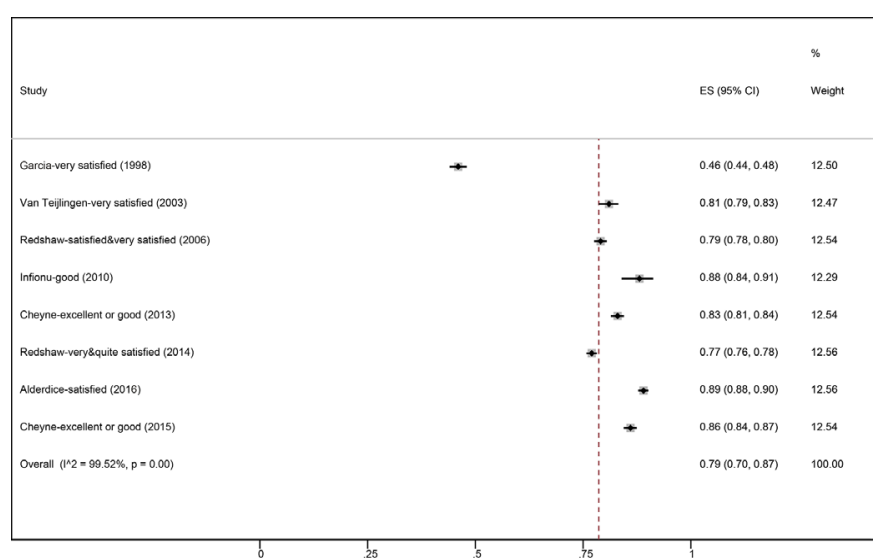

Figure 3 Proportion of women who were satisfied with overall postnatal hospital care. ES, effect size.

groups 37525355596062 and 7 on free-text comments in questionnaires $^{22} 242837405863$; 6 used a mixture of different methods. The majority (18) were conducted in England (or England and Wales), 283337 48-54 57-78 5 were based in Scotland 2440515559 and 2 across the whole of the UK. ${ }^{5356}$ Some questionnaire-based studies which included freetext quotes for illustrative purposes only have not been included here as they were not analysed using qualitative methods.

Most of the studies focused on women's views of maternity care in general rather than their views of hospital postnatal care specifically. Six studies did focus specifically on hospital postnatal care, 334950545665 six others focused on infant feeding, ${ }^{52559-6166}$ and six focused on exploring the experience of ethnic minority women. 335153586064

\section{Risk of bias in qualitative studies}

Only three of the qualitative studies ${ }^{48566}$ appeared to be entirely free from bias (table 4). Although a qualitative method was appropriate throughout, the aims generally specified and the study design was generally appropriate, the recruitment strategy and methods for data collection were sometimes unclear. ${ }^{33} 3750515355-5760-6467$ The relationship between the researcher(s) and participants was only considered in nine studies, ${ }^{485153-5557616566}$ and it was often unclear how rigorous an analysis was carried out. The population was not described in eight studies, ${ }^{2233} 3750-525663$ limiting transferability. In addition, in one study, ${ }^{50}$ interviews were conducted by a research midwife in hospital within a few days of birth, which may have resulted in biased responses. In six studies the analysis was based on free-text comments in postal surveys, ${ }^{22} 2428405863$ in which comments tend to be brief and superficial. However, there was generally a clear statement of the findings and most of the studies could be considered valuable.

\section{Themes from qualitative studies}

\section{Women's expectations}

Seven studies referred to women's expectations of hospital postnatal care. ${ }^{505558-606466}$ None of these studies was prospective, so expectations were asked about or inferred retrospectively. These studies indicated that women often had low expectations of hospital postnatal care, which were sometimes met and sometimes exceeded. $^{5055}$ Ethnic minority women generally expected more support from staff, particularly with breast feeding, and were disappointed. ${ }^{6064}$ Some women reported a lack of balance and honesty regarding antenatal preparation for breast feeding, leading to unrealistic expectations. ${ }^{5966}$

\section{Staff attitudes and behaviour}

This theme, in various forms, emerged in almost all of the qualitative research in this area. Although staff were generally viewed positively, as friendly, helpful and polite, ${ }^{5063}$ other women reported feeling neglected, feeling unable to ask for help as the midwives were perceived as too busy. $^{22} 24283749545565$ Some midwives were reportedly rude or abrupt in their manner, ${ }^{22} 2450$ and ethnic minority women in particular encountered negative staff attitudes and stereotyping. ${ }^{515864}$ Some women who had a particular problem or who had a previous baby felt neglected. ${ }^{49}$

One study focused on interactions between breastfeeding women and midwives on the postnatal ward and used participant observation and focused interviews. ${ }^{54}$ They found that, due in part to time pressures on midwives, they were constrained from developing an 'authentic presence', which led to labelling and stereotyping. Another study reported 'task orientated care' focusing on routine clinical observation. ${ }^{65}$ Emotional relationships with women were often precluded by the organisation of care.

Women were aware that midwives were under pressure and often short-staffed and generally forgiving when this led to delays, even feeling guilty themselves for bothering them. ${ }^{24} 495456$ Delayed discharge was commented on in several studies, ${ }^{22} 248$ women feeling low priority and neglected at this time.

\section{Support}

\section{Emotional support}

Twenty papers $2224333740495053-65$ highlighted the need for emotional support in hospital. After birth women reported that being left alone, continuously needing to ask for help, feeling neglected and being told that the midwife would be back shortly eroded their confidence. $^{22} 244965$ Women reported on the difficulty experienced in having their voices heard and their choices respected. In this theme, the importance of perceived control and related elements such as trust, continuity of care, supportive care and influence over decision making came to the fore. ${ }^{485363}$ Emotional support, not just practical or informational support, was also highlighted in relation to breast feeding. ${ }^{505459-61}$

Women valued reassurance that they were doing well, ${ }^{37}$ and this gave them confidence in looking after themselves and their baby. ${ }^{10}$ Women wanted 'sensitive' care which met their individual needs. They also highlighted the need for practical support in looking after themselves 


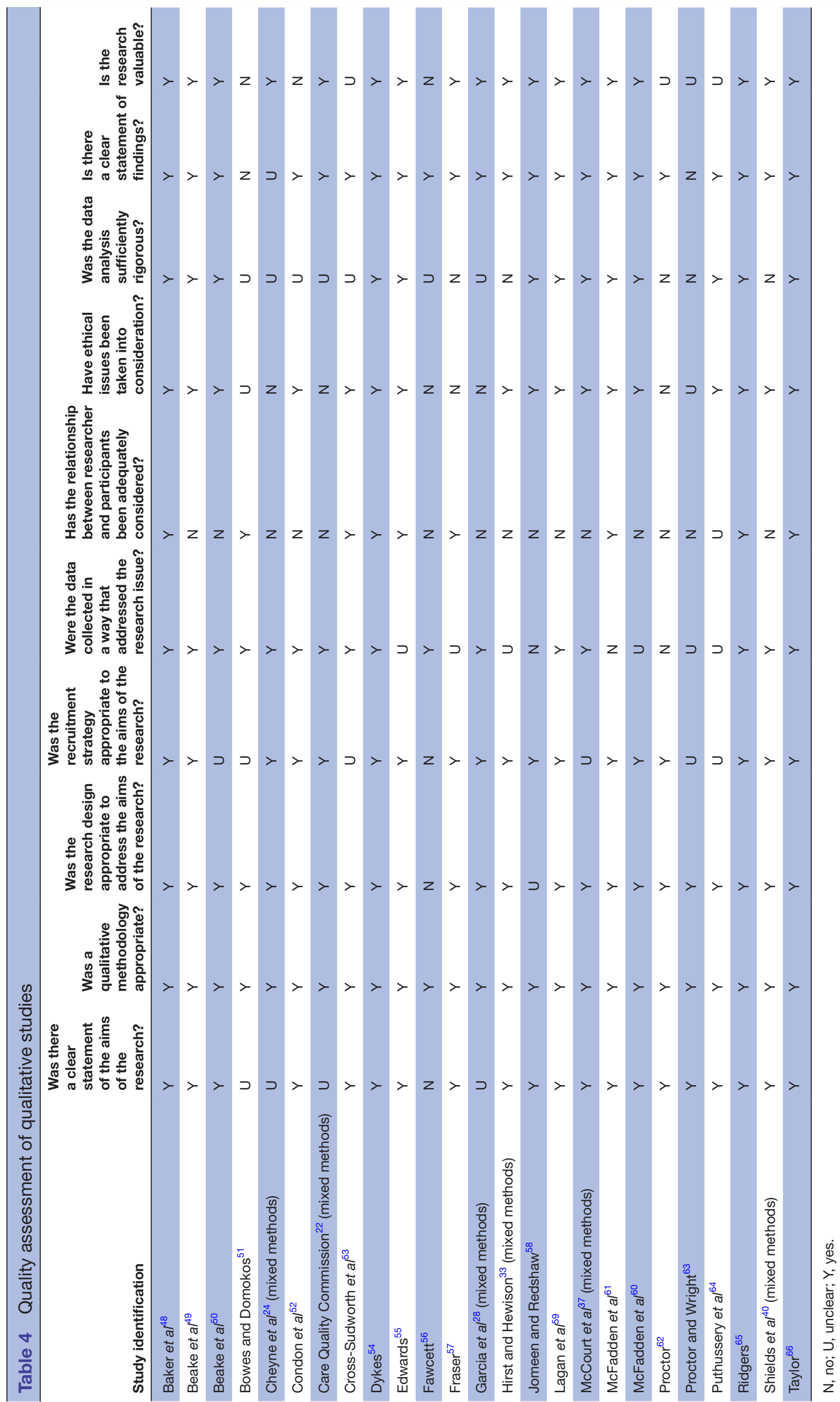

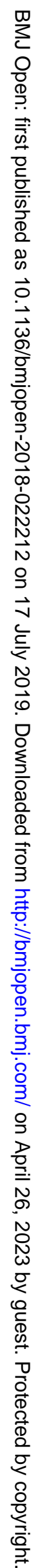


and their baby, particularly those who felt vulnerable, for example after caesarean section. ${ }^{406264}$

\section{Informational support}

Eleven studies reported on aspects of informational support, including inconsistent advice especially in relation to breast feeding. ${ }^{22} 3740495053-55596263$ Women appreciated receiving information about what was happening and about practical aspects of baby care, especially primiparous women, but when this was absent it caused anxiety. ${ }^{40}$ Some women reported a lack of discussion and explanation following complications, ${ }^{22}$ and stressed the importance of being offered information rather than having to probe for it. ${ }^{62}$ The need for specific, detailed information so that women could be involved in decision making and to help them make choices was mentioned in three studies. ${ }^{586263}$

The difficulty in conveying information about breast feeding on wards where midwives are working under pressure was noted. Some midwives felt compelled to achieve information transfer as efficiently as possible, sometimes without assessing comprehension. ${ }^{54}$

\section{Infant feeding}

Although length of hospital stay is now so short as to preclude breast feeding becoming established in hospital, it was nevertheless an important theme in many studies. ${ }^{22} 3748-505254-5659-6166$ There was significant overlap with several of the previous themes, such as staff attitudes and conflicting information. Some women felt harassed and pressurised to breast feed, and made to feel guilty if they could not or chose to formula feed. ${ }^{48} 59$ While some mothers said that midwives were helpful during the initial feed, they said that there was insufficient help during subsequent feeds. ${ }^{52}$ Breast feeding was also sometimes taught in a reductionist way, as a technically managed activity; some midwives physically attached the baby to the breast in a 'hands-on' manner, undermining the woman's confidence in her ability to manage independently. ${ }^{545}$

Conversely, women who were formula feeding sometimes felt neglected and perceived that information about formula feeding was restricted, leading them to feel alienated. ${ }^{59}$ However, in some hospital postnatal wards, formula feeding was normalised, convenience being prioritised over established health benefits. ${ }^{66}$

\section{Ward environment}

This theme relates to a variety of factors in the postnatal ward, including visitors, noise levels, bright lights, temperature, lack of privacy and cleanliness, poor facilities and poor food. Reported comments were almost entirely negative. ${ }^{22} 2433$ 49-51 $5661-6466$

Some women commented on the general lack of orientation regarding the ward environment and routines, not knowing where the showers were, insufficient number of showers ${ }^{49}$ and the lack of cleanliness of the facilities that were available. ${ }^{22} 63$
The issue of visitors was criticised both ways: some women were critical of unrestricted visiting as being too noisy and preventing women from resting. It also created problems with privacy, particularly for women who were breast feeding. ${ }^{49} 505661$ Conversely, other women would have preferred more open visiting, especially for their partner, to provide practical and emotional support when the midwives were too busy to provide this (see below).

Hospital food was criticised by many women, in terms of both quantity and quality. ${ }^{22} 2433$ In particular, women who requested vegetarian or halal food fared poorly, had a lack of choice and had to ask their families to bring food with them when visiting. ${ }^{50} 5164$

Many of the issues associated with the ward environment were perceived as being for the benefit of staff rather than the women.

\section{Discharge}

Six studies highlighted the importance of the transition to home care, and there was again a recognition of the importance of identifying the needs of individual women and vulnerable groups who may not have good family support following discharge. ${ }^{22} 2433535658$ Women who left earlier than they wanted reported that they felt anxious about going home before they were ready. Delayed discharge caused dissatisfaction and frustration with an inefficient service. ${ }^{24} 5056$ Other women commented positively on being able to choose how long they stayed in hospital, not feeling under pressure to leave before they were ready. ${ }^{24}$

\section{Partners}

Only three studies ${ }^{22} 24$ explicitly referred to partners not being able to stay on the postnatal ward as a theme, although others mentioned it in the context of support and visiting. If there were facilities for a woman's partner to stay, and if she had her own room, this resulted in a more positive experience. ${ }^{56}$ Similarly, if the partner did not have unrestricted visiting, particularly if the woman had experienced a complicated or operative delivery, this was associated with a less positive experience. ${ }^{22}{ }^{56}$ Some women reported feeling anxious when their partner had to leave, feeling relatively unsupported on the ward. ${ }^{2456}$

\section{Subgroup analyses}

\section{Subgroup by parity}

Nine quantitative studies 31011182223294246 and one qualitative study ${ }^{55}$ included some data on women's experiences of postnatal care by parity. The majority of these studies looked at length of stay by parity and reported that primiparous women had longer stays than multiparous women. The shortest mean lengths of stay were 2.1 days in primiparous women compared with 1.9 days in multiparous women (Northern Ireland in 2014), ${ }^{18}$ and the longest were 5.8 in primiparous compared with 4.0 in multiparous women (Scotland in 1990-1991). ${ }^{29}$ Women's views of length of stay were also compared in five quantitative studies. ${ }^{3} 10182223$ These all reported that multiparous 
women were more likely to be happy with their length of stay. The biggest disparity was $69 \%$ compared with $75 \%$ of primiparous and multiparous women, respectively, who considered their length of stay about right. ${ }^{22}$ Infant feeding support was examined by parity in four quantitative studies, ${ }^{3} 101822$ and all found that multiparous women reported more consistent advice, support and encouragement, but primiparous women reported more practical help. Multiparous women also reported receiving more information and explanations generally, and specifically about their own recovery, ${ }^{22}$ that staff were kind and treated them as individuals, ${ }^{11}{ }^{23}$ were happier with the ward environment and overall were more satisfied with their postnatal stay. ${ }^{42}$ One qualitative study included eight primiparous women and explored their experience of breast feeding, but there was no comparison with multiparous women. ${ }^{55}$

\section{Subgroup by mode of delivery}

Two quantitative studies reported the mean length of stay by mode of delivery. ${ }^{114}$ Unsurprisingly length of stay was longer following instrumental and operative delivery. A qualitative study examined women's breastfeeding experience following caesarean section. ${ }^{61}$ The results indicate that women underestimated the emotional and physical effects of a caesarean delivery and were reliant on staff to help them breast feed.

\section{Subgroup by length of stay}

One quantitative study included data on satisfaction by length of stay. ${ }^{45}$ The mean length of stay for women who considered their length of stay too long, about right and too short was 3.1 days, 2.6 days and 1.6 days, respectively. Six qualitative studies included length of postnatal stay as a theme or subtheme, ${ }^{22} 2433495356$ but data were not disaggregated by length of stay.

\section{Subgroup by hospital versus birth centre}

There were no studies reporting expectations or experience of postnatal care in birth centres.

\section{Subgroup by time period}

The time periods to be compared were 1970-1989, 19902009 and 2010 to the present. There was only one study conducted prior to $1990^{26}$ so this has been combined with the 1990-2009 period in which there were 23 quantitative studies. Between 2010 and 2017 there were 10 quantitative studies. The decline in mean length of stay is apparent, for example 5.8 days in $1990^{29}$ to 2.1 days in $2014,{ }^{18}$ and also the increase in caesarean sections from $13 \%$ in 1990 to $33 \%$ in 2015 in Scotland ${ }^{24} 29$ and $13 \%$ in 1981 to $26 \%$ in 2014 in England. ${ }^{326}$ One study explicitly examined change over time in women's experience of maternity care using data from four surveys dating from 1995 to $2014 .{ }^{1}$ The proportion of women who considered their length of stay too short remained constant at $12 \%-13 \%$, but always having confidence and trust in postnatal staff fell between 1995 and 2006 from 75\% to $69 \%$. However, support for infant feeding improved considerably over this period, particularly always receiving consistent advice which improved from $31 \%$ in 1995 to $43 \%$ in $2014 .^{1}$ Staff interaction also generally improved. Women reporting that they were always treated as an individual increased from $53 \%$ in $2006^{11}$ to $79 \%$ in $2014,^{18}$ and perceived respect increased from $54 \%$ in $1995^{28}$ to $92 \%$ in $2006^{11}$ before tailing off again to $76 \%$ in $2014 .^{3}$

Thirteen of the qualitative studies were published prior to 2010 and 12 since 2010. However, the themes described did not differ substantively over the time period.

\section{Ethnicity}

Two studies explicitly focused on the perceptions of women from minority ethnic groups. ${ }^{31}{ }^{33}$ These both reported variations in length of postnatal stay and women's views of this. Women from all non-white ethnic groups had longer lengths of stay than white women, but they expected to stay even longer and, except for women of mixed ethnicity, were less likely to consider their length of stay about right. ${ }^{31} 33$

Six qualitative studies focused on the experiences of ethnic minority women on postnatal wards. ${ }^{33} 5153586064$ All except one ${ }^{58}$ which used free-text from a survey were based on interviews with ethnic minority women. Bilingual interviews or interpreters were used as necessary except for one study ${ }^{64}$ which focused on UK-born ethnic minority women. Three main themes emerged in relation to ethnicity:

- Negative staff attitudes and stereotyping were a dominant theme related to ethnicity. ${ }^{51}$ Women reported being treated without kindness, not being listened to or treated as an individual. However, in one study which compared the experiences of Pakistani women with those of white indigenous women, it was the white women who made the most complaints. ${ }^{33}$ Related to this were difficulties with communication due to language or unfamiliarity with the National Health Service (NHS) systems and rules. ${ }^{335153}$ Women were particularly critical of rules forbidding them having their partner stay, leaving them feeling isolated from friends and family. Women also reported a lack of practical support, for example, wanting (and failing) to be shown how to bathe their baby. ${ }^{33} 53$ However, women were reluctant to criticise midwives, recognising that they were busy and not feeling that they have the right to complain. ${ }^{51}$ Running counter to this subtheme, one study reported some more highly educated women feeling empowered and confident. ${ }^{53}$

- Cultural traditions, rest and duration of hospital stay. ${ }^{53}$ In many cultures it is considered appropriate for women to stay in bed and rest for a significant amount of time following childbirth. ${ }^{68}$ However, currently in the NHS women generally stay only 1 or 2 days following a normal delivery, ${ }^{4}$ which women of Asian ethnicity often feel is too short. ${ }^{33}$ Women complained about not getting rest in hospital due to the noise, lights and other babies. ${ }^{33}$ Many women think of hospital as a safe place should anything go 
wrong with either the mother or the baby, so women felt anxious if they were discharged early, particularly if they did not have family nearby ${ }^{58}$ However, some women also reported feeling that the length of stay was too long and that they were bored, particularly if they lacked the social interaction with their partner, friends and family. A further cultural norm in many ethnic minority families is for the baby to be taken away at night to allow the mother to sleep. While this was viewed positively when it occurred,$^{51}$ it is not recommended by the Baby Friendly Initiative, which recommends rooming in ${ }^{69}$ and is now unusual.

- Food and privacy. As noted previously, women who requested vegetarian or halal food were particularly poorly served. ${ }^{51}$ Similarly, while many white women also criticised the wards for a lack of privacy, for ethnic minority women it was a major concern.

\section{DISCUSSION}

\section{Summary of findings}

The main aims of this review were to report on women's satisfaction with hospital/birth centre postnatal care, to explore how this relates to expectations and experience of care, and to identify gaps in hospital postnatal service provision in the UK. We included 53 studies of weak to moderate methodological quality.

The duration of hospital stay after delivery was one of the most commonly discussed outcomes across the included studies. While the length of stay decreased over time, this was not reflected in changes in the level of satisfaction with maternity care. More importance was placed on women having some choice in their duration of stay and the discharge itself not being unduly delayed. This is in keeping with a policy initiative in Canada which offered an increase in postnatal stay up to 60 hours. This showed an increase in satisfaction with postnatal length of stay irrespective of whether or not women chose to stay 60 hours. $^{70}$ While study design limitations necessitate caution in interpretation, Watt $e t a l^{70}$ also found that there was not a large increase in duration of stay as women appeared to leave hospital when they felt ready and there were no changes in maternal or infant health outcomes. Not surprisingly, the ability to exercise some degree of control over care continues to be an important issue in women's satisfaction, and Watt $e t a l \mathrm{~s}^{70}$ studies suggest that it is probably a factor in a woman's decision about how long to stay in hospital.

Staff interaction was generally viewed favourably in both quantitative and qualitative studies. Overall women's perceptions of care, being spoken to so they could understand, feeling listened to and treated as an individual appeared to improve over time. However, many studies reported that midwives did not have enough time to talk to, or otherwise support, women leading to 'task oriented care $^{65}$ and a lack of 'authentic presence'. ${ }^{54}$ A number of recommendations in the NICE guidelines ${ }^{7}$ highlight the need for good communication, for example, asking the woman about her health and well-being and that of her baby, offering consistent information and clear explanations to empower the woman to take care of her own health and that of her baby, and to recognise symptoms that may require discussion, encourage the woman and her family to report any concerns in relation to their physical, social, mental or emotional health, discuss issues, and ask questions. While establishing good communication is a perennial problem in all aspects of care, the lack of time and resources in the face of many tasks would appear to be particularly problematic in achieving these NICE postnatal care recommendations.

Communication and support were also raised in many of the included studies in relation to infant feeding. Women reported receiving conflicting advice, sometimes feeling pressurised to breast feed, and there was also a lack of support and information for women who were formula feeding. Breast feeding was sometimes taught in a reductionist way, and there was a lack of privacy for breast feeding. However, while the data could not be meta-analysed, the quantitative studies suggested an improving picture with regard to consistent advice, practical help and active support, which all increased over time. Interestingly, these problems highlight the focus on informational and practice support on breast feeding in the NICE guidelines and reflect the lack of guidance on providing emotional support related to infant feeding. An international meta-synthesis by Schmied $e t a l^{71}$ emphasised the importance of person-centred communication skills and of relationships in supporting a woman to breast feed, in keeping with the findings of this review. Schmied $e t a l^{71}$ also concluded that organisational systems and services that facilitate continuity of caregiver, for example, continuity of midwifery care or peer support models, are more likely to facilitate supportive care and a trusting relationship with professionals.

Gaps in the literature included the relationship between expectations and experiences, the experiences of minority and vulnerable groups, and the experiences of partners and the wider family. There was only one quantitative study which explicitly explored women's expectations of hospital postnatal care, although seven qualitative studies included some reference to this. Wider maternity care literature suggests that expectations impact on our experience of care ${ }^{72}$ However, from the current review, it is unclear if the lower satisfaction with postnatal care, in comparison with antenatal or intrapartum care, is related to unmet expectations, poor experience of birth or after giving birth, or the emotional or physical well-being of the women reporting their experiences.

Over 20yearsago, theWHOrecommended that care after childbirth should include all family members ${ }^{73}$; however, partners' experience of postpartum care has received little attention. The Royal College of Midwives in collaboration with the Royal College of Obstetricians and Gynaecologists, the Department of Health and the Fatherhood Institute produced a paper highlighting the importance of making opportunities to explore and discuss both the mother's and father's experiences of childbirth and early 
parenting. ${ }^{74}$ The paper also identified the need to provide health education and support to both parents, covering general health and well-being advice such as nutrition, exercise, rest and relaxation, healthy lifestyle habits, and contraception. From this review it is clear that, in the UK, early postnatal care is not designed to involve partners despite being noted as a priority by the NICE guidelines.

\section{Strengths and limitations}

This is an up-to-date systematic review reflecting on women's experiences of postnatal care in hospitals in the UK. The search strategy was broad and covered 10 different databases. The methods were rigorous, and quality assessment and data extraction were performed by authors independently of each other.

Although we set out to review the literature relating to postnatal care for women at low risk of complications to explore routine practice, this was not always possible. Most of the studies reported results undifferentiated by risk and without excluding those women at high risk. Similarly, this review has focused on postnatal care in hospital, but for some outcomes, particularly those relating to infant feeding, it was not possible to separate hospital from community care. These studies were included for completeness.

The breadth of the review was a strength in terms of a comprehensive assessment of existing literature, but this also limited the ability to meta-analyse the data in a meaningful way due to heterogeneity.

\section{Implications for research}

The review identified a number of gaps in the literature that would benefit from additional research. Although several large surveys included women who delivered in birth centres, no studies were found which specifically explored women's experience of postnatal care in these settings. This would be a topic worth exploring, particularly as there has been an increase in the number of birth centres in the UK over time. Further research is also required to explore the experiences of women with more complex needs. For example, there was some evidence that women were more critical of their care following an operative delivery or following complications in childbirth, when they expected that physical help and support would be more forthcoming.

Priority should be given to developing a stronger evidence base to guide postnatal hospital care in areas such as length of hospital stay, the use of clinical pathways, involvement of partners, and the nature and timing of routine observations of the mother and the baby to enhance the provision of individualised care. Schmied and Bick ${ }^{75}$ highlighted a number of potential strategies that might improve care, including planning for the postnatal period during pregnancy, development of consumer-written information, introduction of new handheld records to prompt individualised care, and offering daily 'One to One' time in which a midwife listens to a woman's needs and discusses issues related to their health and that of their baby. Such initiatives are promising but require rigorous evaluation.

Also when conducting evaluations we need to rethink how to measure the main outcomes of postnatal care. The so-called 'hard outcomes' such as maternal morbidity and breastfeeding initiation remain important but, building on our review findings, we need to detect other aspects that are important to women, including discharge readiness, parenting confidence and psychological wellbeing (both positive and negative aspects).

\section{Policy implications}

The review suggests that current approaches, such as fixed length of stay, may inhibit rather than support individualised care for women after childbirth and that a move towards greater flexibility in the organisation and provision of care would be valued by women. Hospital care was widely perceived by women to be complex, busy and under-resourced, which allowed for limited investment in effective psychosocial support to women and their families at this key time just after birth. Studies of women's views of maternity care have consistently found that hospital postnatal care is poorly rated compared with other areas of maternity care. In line with the recommendations from Better Births ${ }^{8}$ and the Maternity Transformation Programme, ${ }^{9}$ strategies are needed to optimise women's experiences, including improving communication and information giving, involving women in decisions regarding their length of stay, and continuing to improve feeding support. NICE postnatal care guidelines are currently being reviewed and updated, which provides an important opportunity to reflect on our current model of care and its limitations.

The review also highlights that more needs to be done to integrate partners into postnatal hospital care policy. Partners are important as supporters and a resource for the mother ${ }^{76}$ and as a recipient of care. ${ }^{77} \mathrm{~A}$ number of other groups were also identified who would benefit from additional research and policy attention, for example, primiparous women, those with complex needs, those from ethnic minorities and other vulnerable groups.

Much of the research in this review suggests that staff shortages have placed midwives under too great a pressure to provide a good service. This clearly has resource implications, but this must be considered for realistic strategic future planning. If we want to see further reductions in maternal and perinatal mortality and improved experiences of care, much more needs to be done to establish effective care particularly in the early days after birth.

\section{CONCLUSIONS}

This review suggests that the majority of women in the UK were generally happy with their hospital postnatal care. The results of this review suggest that there are areas of hospital postnatal care that could be improved to ensure that the first days after birth establish good maternal and infant health and well-being. 
Acknowledgements Our thanks to Maggie Redshaw and Merryl Harvey for commenting on a draft manuscript and Charles Opondo for his assistance with the meta-analyses and forest plots. Thank you also to our PPPI stakeholder network for their ongoing contribution to dissemination of findings.

Contributors FA conceived the idea and planned the project. FA, JH and RM developed the protocol, and RM developed the search strategy. RM, JH and FA screened the search results and full papers, assessed the quality of included papers, extracted the data and synthesised the results. RM, JH and FA drafted the manuscript, and all authors agreed on the final manuscript. RM conducted the search update. RM and FA screened and extracted the updated results, and RM, JH and FA agreed on the revised manuscript.

Funding This paper reports on an independent study whichwas funded by the Policy Research Programme in the Department of Health. The views expressed are not necessarily those of the Department. The Department of Health was not involved in any aspect of the study.

Disclaimer The views expressed are not necessarily those of the Department.

Competing interests None declared.

Patient consent for publication Not required.

Provenance and peer review Not commissioned; externally peer reviewed.

Data sharing statement All the data included in this systematic review are in the public domain.

Open access This is an open access article distributed in accordance with the Creative Commons Attribution Non Commercial (CC BY-NC 4.0) license, which permits others to distribute, remix, adapt, build upon this work non-commercially, and license their derivative works on different terms, provided the original work is properly cited, appropriate credit is given, any changes made indicated, and the use is non-commercial. See: http://creativecommons.org/licenses/by-nc/4.0/.

\section{REFERENCES}

1. Henderson J, Redshaw M. Change over time in women's views and experiences of maternity care in England, 1995-2014: A comparison using survey data. Midwifery 2017;44:35-40.

2. Rush JCl, Enkin M. Care of the new mother and baby. In: Chalmers IEM, Keirse M, eds. Effective care in pregnancy and childbirth. Oxford: Oxford University Press, 1989:1341-4.

3. Redshaw M, Henderson J. Safely delivered: a national survey of women's experience of maternity care 2014. Oxford 2015.

4. NHS Digital. Hospital Maternity Activity, 2015-16 London: NHS Digital. 2016 http://digital.nhs.uk/catalogue/PUB22384

5. Brown S, Small R, Faber B, et al. Early postnatal discharge from hospital for healthy mothers and term infants. Cochrane Database Syst Rev 2002;3:CD002958.

6. Waldenström U, Sundelin C, Lindmark G. Early and late discharge after hospital birth: breastfeeding. Acta Paediatr Scand 1987;76:727-32.

7. National Institute for Health and Care Excellence. Postnatal care up to 8 weeks after birth. London: NICE, 2006.

8. NHS England. National Maternity Review. Better Births. Improving outcomes of maternity services in England. London, 2016.

9. NHS England. Maternity Transformation Programme London: NHS England. 2017 https://www.england.nhs.uk/mat-transformation/

10. Redshaw M, Heikkila K. Delivered with care: a national survey of women's experiences of maternity care 2010. Oxford: NPEU, 2010.

11. Redshaw M, Rowe R, Hockley C, et al. Recorded delivery: a national survey of women's experiences of maternity care 2006. Oxford: NPEU, 2006.

12. Liberati A, Altman DG, Tetzlaff J, et al. The PRISMA statement for reporting systematic reviews and meta-analyses of studies that evaluate healthcare interventions: explanation and elaboration. BMJ 2009;339:b2700.

13. National Institute of Health and Care Excellence. Antenatal care for uncomplicated pregnancies. 2017 https://www.nice.org.uk/guidance/ $\operatorname{cg} 62$

14. Cooke A, Smith D, Booth A. Beyond PICO: the SPIDER tool for qualitative evidence synthesis. Qual Health Res 2012;22:1435-43.

15. National Institute for Health. Quality Assessment Tool for Observational Cohort and Cross-Sectional Studies. https://www. nhlbi.nih.gov/health-pro/guidelines/in-develop/cardiovascular-riskreduction/tools/cohort2017

16. Critical Appraisal Skills Programme. CASP Qualitative Checklist. 2017 http://www.casp-uk.net/casp-tools-checklists;
17. Dixon-Woods M, Bonas S, Booth A, et al. How can systematic reviews incorporate qualitative research? A critical perspective. Qualitative Research 2006;6:27-44.

18. Alderdice F, Hamilton K, McNeill J, et al. Birth NI: a survey of women's experience of maternity care in Northern Ireland. Belfast: Queen's University Belfast, 2016.

19. Bick D, Murrells T, Weavers A, et al. Revising acute care systems and processes to improve breastfeeding and maternal postnatal health: a pre and post intervention study in one English maternity unit. BMC Pregnancy Childbirth 2012;12:41.

20. Bowers J, Cheyne $\mathrm{H}$. Reducing the length of postnatal hospital stay: implications for cost and quality of care. BMC Health Serv Res 2016;16:16:16.

21. Care Quality Commission. Women's experiences of maternity care in England: key findings from the 2010 NHS trust survey. 2010 www. cqc.org.uk/sites/default/files/media/documents/20101201_mat10_ briefing final for publication_201101072550.pdf

22. Care Quality Commission. National findings from the 2013 survey of women's experiences of maternity care. London: CQC, 2013.

23. Care Quality Commission. 2015 survey of women's experience of maternity care. Statistical release. London: CQC, 2015.

24. Cheyne $\mathrm{H}$, Critchley $\mathrm{A}$, Elders $\mathrm{A}$, et al. Having a baby in Scotland 2015: listening to mothers. National report. Edinburgh: NHS Scotland, 2015.

25. Cheyne H, Skår S, Paterson A, et al. Having a baby in Scotland 2013 women's experiences of maternity care. National report. Edinburgh: NHS Scotland, 2013.

26. Cranfield FM. Survey of postnatal care. J R Soc Med 1983;76:41-4.

27. Farquhar M, Camilleri-Ferrante $C$, Todd C. Continuity of care in maternity services: women's views of one team midwifery scheme. Midwifery 2000;16:35-47.

28. Garcia J, Redshaw M, Fitzsimons B, et al. First class delivery: a national survey of women's views of maternity care. Audit Commission, NPEU: Oxford, 1998.

29. Glazener C. Investigation of postnatal experience and care in Grampian: University of Aberdeen, 1999

30. Healthcare Commission. Women's experiences of maternity care in the NHS in England. London: Commission for Healthcare Audit and Inspection, 2007.

31. Henderson J, Gao H, Redshaw M. Experiencing maternity care: the care received and perceptions of women from different ethnic groups. BMC Pregnancy Childbirth 2013;13:196.

32. Hicks C, Spurgeon P, Barwell F. Changing Childbirth: a pilot project. $J$ Adv Nurs 2003;42:617-28.

33. Hirst J, Hewison J. Hospital postnatal care: obtaining the views of Pakistani and indigenous 'white' women. Clinical Effectiveness in Nursing 2002;6:10-18.

34. Hundley V, Rennie AM, Fitzmaurice A, et al. A national survey of women's views of their maternity care in Scotland. Midwifery 2000;16:303-13.

35. Ifionu J, Hamouda T, Saleh M. A survey of the quality of maternity care at the Norfolk \& Norwich University Hospital NHS Foundation Trust. Arch Dis Child Fetal Neonatal Ed 2010;95:Fa99.

36. Ingram J, Johnson D, Greenwood R. Breastfeeding in Bristol: teaching good positioning, and support from fathers and families. Midwifery 2002;18:87-101.

37. McCourt C, Page L, Hewison J, et al. Evaluation of one-to-one midwifery: women's responses to care. Birth 1998;25:73-80.

38. Raleigh VS, Hussey D, Seccombe I, et al. Ethnic and social inequalities in women's experience of maternity care in England: results of a national survey. $J$ S Soc Med 2010;103:188-98.

39. Scott PA, Taylor A, Välimäki M, et al. Autonomy, privacy and informed consent 2: postnatal perspective. Br J Nurs 2003;12:117-27.

40. Shields N, Turnbull D, Reid M, et al. Satisfaction with midwifemanaged care in different time periods: a randomised controlled trial of 1299 women. Midwifery 1998;14:85-93.

41. Spurgeon P, Hicks C, Barwell F. Antenatal, delivery and postnatal comparisons of maternal satisfaction with two pilot Changing Childbirth schemes compared with a traditional model of care. Midwifery 2001;17:123-32.

42. van Teijlingen ER, Hundley V, Rennie AM, et al. Maternity satisfaction studies and their limitations: "What is, must still be best". Birth 2003;30:75-82

43. Wardle S. Getting consumers' views of maternity services. Professional Care of Mother \& Child 1994;4:170-4.

44. Wray J. Seeking to explore what matters to women about postnatal care. British Journal of Midwifery 2006;14:246-54.

45. Dowswell T, Piercy J, Hirst J, et al. Short postnatal hospital stay: implications for women and service providers. J Public Health Med 1997;19:132-6. 
46. National Childburth Trust. Left to your own devices: the postnatal care experiences of 1260 first-time mothers. London: NCT, 2010.

47. Care Quality Commission. 2018 survey of women's experiences of maternity care. 2019 https://wwwcqcorguk/publications/surveys/ maternity-services-survey-2018

48. Baker SR, Choi PYL, Henshaw CA, et al. 'I Felt as though I'd been in Jail': Women's Experiences of Maternity Care during Labour, Delivery and the Immediate Postpartum. Fem Psychol 2005;15:315-42.

49. Beake S, McCourt C, Bick D. Women's views of hospital and community-based postnatal care: the good, the bad and the indifferent. Evidence Based Midwifery 2005;3:80-6.

50. Beake S, Rose V, Bick D, et al. A qualitative study of the experiences and expectations of women receiving in-patient postnatal care in one English maternity unit. BMC Pregnancy Childbirth 2010;10:70.

51. Bowes AM, Domokos TM. Pakistani women and maternity care: raising muted voices. Sociology of Health \& IIIness 1996;18:45-65.

52. Condon L, Rhodes C, Warren S, et al. 'But is it a normal thing?' Teenage mothers' experiences of breastfeeding promotion and support. Health Education Journal 2013;72:156-62.

53. Cross-Sudworth F, Williams A, Herron-Marx S. Maternity services in multi-cultural Britain: using $Q$ methodology to explore the views of first- and second-generation women of Pakistani origin. Midwifery 2011;27:458-68.

54. Dykes F. A critical ethnographic study of encounters between midwives and breast-feeding women in postnatal wards in England. Midwifery 2005;21:241-52.

55. Edwards ME. Confidence in initiation of breastfeeding: University of Stirling, 2013.

56. Fawcett J. The impact of postnatal care on a woman's overall maternity experience: an analysis of stories from Patient Opinion. Sheffiel: Sheffield Medical School, 2016.

57. Fraser DM. Women's perceptions of midwifery care: a longitudinal study to shape curriculum development. Birth 1999;26:99-107.

58. Jomeen J, Redshaw M. Ethnic minority women's experience of maternity services in England. Ethn Health 2013;18:280-96.

59. Lagan BM, Symon A, Dalzell J, et al. 'The midwives aren't allowed to tell you': perceived infant feeding policy restrictions in a formula feeding culture - the Feeding Your Baby Study. Midwifery 2014;30:e49-55.

60. McFadden A, Renfrew MJ, Atkin K. Does cultural context make a difference to women's experiences of maternity care? A qualitative study comparing the perspectives of breast-feeding women of Bangladeshi origin and health practitioners. Health Expect 2013;16:e124-35.

61. McFadden C, Baker L, Lavender T. Exploration of factors influencing women's breastfeeding experiences following a caesarean section. Evidence Based Midwifery 2009;7:64-70.
62. Proctor $\mathrm{S}$. What determines quality in maternity care? Comparing the perceptions of childbearing women and midwives. Birth 1998;25:85-93.

63. Proctor S, Wright G. Consumer responses to health care: women and maternity services. Int J Health Care Qual Assur Inc Leadersh Health Serv 1998;11:147-55.

64. Puthussery S, Twamley K, Macfarlane A, et al. 'You need that loving tender care': maternity care experiences and expectations of ethnic minority women born in the United Kingdom. $J$ Health Serv Res Policy 2010;15:156-62.

65. Ridgers MI. 'Passing through but needing to be heard' an ethnographic study of women's perspectives of their care on the postnatal ward: Bournemouth University, 2007.

66. Taylor CA. Post-natal care and breastfeeding experiences: a qualitative investigation following a randomised trial of side-car crib use (NECOT Trial: Durham University, 2014.

67. Jomeen J, Redshaw M. Black and minority ethnic women's experiences of contemporary maternity care in England. J Reprod Infant Psychol 2011;29:e9.

68. Katbamna S. 'Race' and childbirth. Buckingham: Open University Press, 2000.

69. Baby Friendly Hospital Initiative. Ten steps to successful breastfeeding. $2013 \mathrm{http} / / /$ www.tensteps.org/ten-steps-successfulbreastfeeding.shtml

70. Watt S, Sword W, Krueger P. Longer postpartum hospitalization options--who stays, who leaves, what changes? BMC Pregnancy Childbirth 2005;5:13

71. Schmied V, Beake S, Sheehan A, et al. Women's perceptions and experiences of breastfeeding support: a metasynthesis. Birth 2011;38:49-60.

72. Green JM, Coupland VA, Kitzinger JV. Great expectations (2nd edn): Books for Midwives Press, 1998.

73. World Health Organisation (WHO). Postpartum care of the mother and newborn: a practical guide. $1998 \mathrm{https}: / / \mathrm{www} w h o i n t /$ maternal child_adolescent/documents/who_rht_msm_983/en/

74. Royal College of Midwives. Reaching out: Involving fathers in maternity care. $2011 \mathrm{https}: / /$ wwwrcmorguk/sites/default/files/ Father's\%20Guides\%20A4_3_0pdf

75. Schmied V, Bick D. Postnatal care - current issues and future challenges. Midwifery 2014;30:571-4.

76. Persson EK, Dykes AK. Parents' experience of early discharge from hospital after birth in Sweden. Midwifery 2002;18:53-60.

77. Ellberg L, Högberg U, Lindh V. 'We feel like one, they see us as two': new parents' discontent with postnatal care. Midwifery 2010;26:463-8.

78. Turnbull D, Holmes A, Shields N, et al. Randomised, controlled trial of efficacy of midwife-managed care. Lancet 1996;348:213-8. 